\title{
Can We Resurrect the CAPM in Japan? Evaluating Conditional Asset Pricing Models by Incorporating Time-varying Price of Risk
}

\author{
Chikashi Tsuji \\ Graduate School of Systems and Information Engineering, University of Tsukuba \\ 1-1-1 Tennodai, Tsukuba, Ibaraki 305-8573, Japan \\ Tel: 81-29-853-2111 E-mail: mail_sec_low@minos.ocn.ne.jp
}

\begin{abstract}
This paper evaluates conditional asset pricing models for the Japanese stock market by examining time-varying risk pricing. Using a multivariate generalized autoregressive conditional heteroskedasticity $(\mathrm{GARCH})$ model, we tested the conditional versions of the Sharpe (1964)-Lintner (1965)-Mossin (1966) capital asset pricing model (CAPM), the consumption CAPM (CCAPM), and the CAPM with a constant term. The empirical results demonstrate that the price of risk in the conditional CAPM is generally positive and significant. Moreover, our formal panel data tests reveal that the conditional CAPM is never rejected in the case of the 25 book-equity-to-market equity (BE/ME)-ranked portfolios. Furthermore, in the conditional version of the CAPM with a constant term, positive alphas are generally seen in Japan; however, our statistical test of the hypothesis that the average value of the alphas of the conditional CAPM equals zero is never rejected for the 25 BE/ME-ranked portfolios in Japan. This evidence demonstrates that the CAPM can be adequately represented by using the multivariate $\mathrm{GARCH}$ model to explain the value premia in Japan.
\end{abstract}

Keywords: Conditional CAPM, Conditional consumption CAPM, Jensen's alpha, Multivariate GARCH model, Panel data analysis, Time-varying price of risk, Time-varying alpha 


\section{Introduction}

The time-varying characteristics of both covariance risk and the price of risk are clearly crucial for asset pricing. There is substantial empirical evidence that the level of risk varies over time (Bollerslev et al. (1988), Harvey (1989), Ng (1991), and Zhou (1994), amongst others). However, in many earlier studies, covariance risk is focused on and regarded as time-varying, but not much attention is paid to the price of risk.(Note 1) Thus, the dynamics of the risk price and the degree of pricing of the risk from a time-series viewpoint appears to be unclear in existing work.(Note 2) Price of risk is important because the risk price of the capital asset pricing model (CAPM) has the economic meaning of the relative risk aversion and also the risk price generally means the reward for taking risks in practical investments. Therefore, research on asset pricing focusing on the time-varying risk price rather than on time-varying risk is required. This will contribute to a wider body of research in the field of finance, and this is the first motive of this research.

Our second motive relates to the ongoing debate regarding the conditional CAPM and the conditional consumption-based CAPM (CCAPM). Some authors, such as Jagannathan and Wang (1996), Lettau and Ludvigson (2001), Ang and Chen (2007), and Petkova and Zhang (2005), find that conditional models help explain the cross-section of stock returns. However, other authors, such as Lewellen and Nagel (2006) and Fama and French (2006), argue that the conditional models have had very limited success. It is also pointed out that the testing methodologies that the above studies employ are not always the same, however, the Generalized Method of Moments (GMM) approach is typical. This situation requires additional research as to the effectiveness of conditional asset pricing models using methods other than the typical GMM approach.

Thus, in this paper, we attempt to participate in the ongoing debate by testing the conditional versions of the Sharpe (1964)-Lintner (1965)-Mossin (1966) CAPM, the CCAPM (Breeden (1979), Merton (1973), and Rubinstein (1976)), and the CAPM with a constant term (Hereafter, we call this model the alpha CAPM.) by focusing on the risk prices. We also employ a different methodology by using the multivariate generalized autoregressive conditional heteroskedasticity $(\mathrm{GARCH})$ model, which enables us to incorporate a time-varying risk price into our empirical tests. Furthermore, the use of this multivariate GARCH model in asset pricing seems to be limited.(Note 3)

More directly, this paper has two goals. The first is to clarify the degree of statistical significance of the monthly time-varying price of risk in the conditional version of CAPM, alpha CAPM, and CCAPM in Japan. The second is to judge the empirical validity of the above three conditional models in Japan using a multivariate GARCH model.(Note 4)

To achieve the above goals, we construct two sets of 25 portfolios, which are formed by BE/ME (book-equity-to-market equity) and by size following Fama and French (1993).(Note 5) We then use a multivariate GARCH model(Note 6) to derive the time-varying covariance risk. By exploiting the covariances and performing monthly cross-sectional regressions for Japan, we examine the monthly time-varying risk prices. Furthermore, in addition to a monthly analysis, we also test risk pricing and compare models using panel data analysis. 
Moreover, we also test whether the averages of the time-varying alphas(Note 7) are zero in the conditional CAPM. The above latter two tests attempt to answer the criticisms of the testing methodologies of Lewellen and Nagel (2006) and Fama and French (2006).(Note 8)

On the basis of our motives, goals, and approach, the findings derived in this paper are as follows. First, from the viewpoint of risk pricing, we demonstrate that the conditional covariance risk from a multivariate GARCH model is generally positively priced in the conditional CAPM in Japan.

Second, our monthly test of the time-varying risk price revealed that the conditional CCAPM is not supported in Japan.

Third, from the viewpoint of model evaluation, again, our formal $F$-test rejects the traditional conditional CCAPM against the conditional CAPM and the conditional alpha CAPM in Japan.

Fourth, in our model evaluation tests, in Japan, we find that the positive alpha is generally recognized. In our panel data analysis, mainly because of the effects of a positive alpha, the conditional CAPM is sometimes rejected and the conditional alpha CAPM is supported in explaining the size effect in Japan. However, the conditional CAPM is never rejected and the conditional alpha CAPM is rejected in all cases in explaining the value effect in Japan. This evidence is very similar to the results for the US of Ang and Chen (2007), and is different from the results for the US of Fama and French (2006).(Note 9)

Fifth, we also test the existence of a non-zero alpha in the conditional CAPM, which is often criticized (e.g. Lewellen and Nagel (2006) and Fama and French (2006)). We confirm that the non-zero alpha hypothesis is not supported in the tests used for the BE/ME portfolios in Japan. Thus, we suggest that when the time-varying risk price, derived using the multivariate GARCH model, is incorporated into the tests, the performance of the conditional CAPM adequately explains the value effect in Japan.

The remainder of this paper is organized as follows. Section 2 describes the models we test in this paper. Section 3 documents the economic background of our research. Section 4 presents the methodology and Section 5 describes the data. The empirical results and their interpretation are supplied in Sections 6 and 7. Comparisons with other influential studies are performed in Section 8. Section 9 presents our conclusions.

\section{Model}

As mentioned, we focus on three traditional conditional models in this article. The first is the conditional CAPM. The model for period $t$ is an equilibrium relation for the conditional expected return of an asset in excess of the risk-free rate when agents use the information available at the end of period $t-1$ :

$$
E\left[\left(r_{i, t}-r_{f, t}\right) \mid \Omega_{t-1}\right]=\frac{E\left[\left(r_{m, t}-r_{f, t}\right) \mid \Omega_{t-1}\right]}{\operatorname{Var}\left[r_{m, t} \mid \Omega_{t-1}\right]} \operatorname{Cov}\left[r_{i, t}, r_{m, t} \mid \Omega_{t-1}\right]
$$




$$
\begin{array}{r}
=\beta_{i, t} E\left[\left(r_{m, t}-r_{f, t}\right) \mid \Omega_{t-1}\right] . \\
\beta_{i, t} \equiv \frac{\operatorname{Cov}\left[r_{m, t}, r_{i, t} \mid \Omega_{t-1}\right]}{\operatorname{Var}\left[r_{m, t} \mid \Omega_{t-1}\right]},
\end{array}
$$

where $r_{i, t}$ and $r_{m, t}$ are the one-period returns on an asset and the market portfolio, respectively, $r_{f, t}$ is the one-period risk-free rate, and $\Omega_{t-1}$ is the information available in markets at time $t-$ 1.(Note 10)

The conditional CAPM is a static one-period model that holds period by period. It is also a generalization of the one-period CAPM developed by Sharp-Lintner-Mossin. In this paper, we do not assume that the market price of risk is stable over time, but rather assume that it is time varying:

$$
\delta_{t} \equiv \frac{E\left[\left(r_{m, t}-r_{f, t}\right) \mid \Omega_{t-1}\right]}{\operatorname{Var}\left[r_{m, t} \mid \Omega_{t-1}\right]} .
$$

Thus, different from other studies, we have the following conditional version of the Sharp-Lintner-Mossin CAPM for a single asset $i$ :

$$
E\left[\left(r_{i, t}-r_{f, t}\right) \mid \Omega_{t-1}\right]=\delta_{t} \operatorname{Cov}\left[r_{i, t}, r_{m, t} \mid \Omega_{t-1}\right]
$$

In this formulation, the estimation of the time-varying covariance, $\operatorname{Cov}\left[r_{i, t}, r_{m, t} \mid \boldsymbol{\Omega}_{t-1}\right]$, is necessary for evaluating this model and, by inspecting the statistical significance of $\delta_{t}$ using these covariances, we can judge whether the covariance risk is priced. Thus, testing using this model is the first method of analysis for our empirical work. Model (4) allows us to statistically implement the intertemporal capital asset pricing model (ICAPM), and we provide more economic foundations and background for our tests in Section 3.

Our second model for analysis is model (5) below, which could be interpreted as the conditional version of the CAPM with a constant term (the conditional alpha CAPM):

$$
E\left[\left(r_{i, t}-r_{f, t}\right) \mid \Omega_{t-1}\right]=\alpha_{t}+\delta_{t} \operatorname{Cov}\left[r_{i, t}, r_{m, t} \mid \Omega_{t-1}\right]
$$

where $\alpha_{t}$, the time-varying alpha, is a common intercept for all portfolios and again, we assume a time-varying risk price, $\delta_{t}$.

The third model is the following conditional version of the consumption CAPM:

$$
E\left[\left(r_{i, t}-r_{f, t}\right) \mid \Omega_{t-1}\right]=\lambda_{t} \operatorname{Cov}\left[r_{i, t}, \Delta c_{t} \mid \Omega_{t-1}\right]
$$

Again, we assume that the price of consumption covariance risk, $\lambda_{t}$, is time varying. Here, $\operatorname{Cov}\left[r_{i, t}, \Delta c_{t} \mid \Omega_{t-1}\right]$ is the covariance between the return of an asset $i$ and changes in consumption. 


\section{Economic Background}

As we emphasized in Sections 1 and 2, our focus is the time-varying risk price in this paper. Apart from the viewpoint of econometrics or model evaluation, how then is it economically important?

As Merton $(1973,1980)$ and Cochrane (2005) suggest, the price of risk from the CAPM can be interpreted as the coefficient of relative risk aversion of investors. Specifically, Cochrane (2005) expresses the ICAPM as:

$$
E_{t}\left(R_{t+1}^{i}\right)-R_{t}^{f} \approx \operatorname{rra}_{t} \operatorname{cov}_{t}\left(R_{t+1}^{i}, \Delta W_{t+1} / W_{t}\right)+\lambda_{z t} \operatorname{cov}_{t}\left(R_{t+1}^{i}, \Delta z_{t+1}\right)
$$

where $E_{t}\left(R_{t+1}^{i}\right)$ is the conditional expected return of asset $i, R_{t}^{f}$ is the risk-free rate, $r r a_{t}$ is the relative risk aversion coefficient, $\operatorname{cov}_{t}\left(R_{t+1}^{i}, \Delta W_{t+1} / W_{t}\right)$ is the conditional covariance between the return of asset $i$ and the change in wealth (or return on the market portfolio), $\operatorname{cov}_{t}\left(R_{t+1}^{i}, \Delta z_{t+1}\right)$ is the conditional covariance between the return of asset $i$ and the change in state variable $z$, and $\lambda_{z t}$ is the risk price for the state variable.

Thus, in the context of our research, in particular, the time-varying price of risk $\delta_{t}$ from the conditional CAPM (4) and the conditional alpha CAPM (5) can be interpreted as the time-varying risk aversion of the market participants as per Cochrane's (2005) $\delta_{t}$ as $r r a_{t}$ in equation (7).

This notion of time-varying risk aversion is used for example by Abel (1990), Constantinides (1990), Campbell and Cochrane (1999), and Li (2007). Recently, this concept has received increasing attention, and is important to research in both finance and economics.

Furthermore, from a practical viewpoint, we assume that the time-varying risk price is more important than time-varying covariance risk. Because if the time-varying risk is not priced, the risks taken by investors are never rewarded by a premium in asset returns. Therefore, as mentioned above, the time-varying price of risk is crucial for both academic researchers and practitioners in that 1) it has significant economic interpretation, and 2) it helps investors decide whether the risks are worth taking or are meaningless in actual equity investment situations.

\section{Methodology}

As the excellent survey by Bauwens et al. (2006) argues, the multivariate GARCH model is crucially important in the context of asset pricing because the model is useful for calculating the time-varying covariances or factor loadings (Lundblad (2007) and Bali (2008), amongst others).

To evaluate the time-varying risk prices, $\delta_{t}$ and $\lambda_{t}$ above, we first estimate the time-varying covariances, $\operatorname{Cov}\left[r_{i, t}, r_{m, t} \mid \Omega_{t-1}\right]$ and $\operatorname{Cov}\left[r_{i, t}, \Delta c_{t} \mid \Omega_{t-1}\right]$, by the multivariate BEKK GARCH 
model (Engle and Kroner (1995), Kroner and Ng (1998)). The BEKK model ensures that the $\mathbf{H}$ matrix is always positive definite, and is specified by:

$$
\mathbf{H}_{\mathrm{t}}=\mathbf{W}+\mathbf{B}^{\prime} \mathbf{H}_{\mathrm{t}-1} \mathbf{B}+\mathbf{A}^{\prime} \Xi_{\mathrm{t}-1} \Xi_{\mathrm{t}-1}^{\prime} \mathbf{A}
$$

where $\mathbf{W}, \mathbf{A}$, and $\mathbf{B}$ are $2 \times 2$ matrices of parameters, and $\mathbf{W}$ is assumed to be symmetric and positive definite.

For the purpose of clarity, in the case of two assets, we define the matrices as follows:

$$
\begin{array}{r}
\mathbf{H}_{\mathbf{t}}=\left[\begin{array}{ll}
h_{11, t} & h_{12, t} \\
h_{12, t} & h_{22, t}
\end{array}\right], \mathbf{W}=\left[\begin{array}{ll}
w_{11} & w_{12} \\
w_{12} & w_{22}
\end{array}\right], \mathbf{A}=\left[\begin{array}{ll}
a_{11} & a_{12} \\
a_{21} & a_{22}
\end{array}\right], \\
\mathbf{B}=\left[\begin{array}{ll}
b_{11} & b_{12} \\
b_{21} & b_{22}
\end{array}\right], \mathbf{\Xi}_{\mathbf{t}}=\left[\begin{array}{l}
u_{1, t} \\
u_{2, t}
\end{array}\right] ;
\end{array}
$$

the model is then written in full as:

$$
\begin{aligned}
h_{11, t}= & w_{11}+a_{11}^{2} u_{1, t-1}^{2}+a_{21}^{2} u_{2, t-1}^{2}+2 a_{11} a_{21} u_{1, t-1} u_{2, t-1} \\
& +b_{11}^{2} h_{11, t-1}+b_{21}^{2} h_{22, t-1}+2 b_{11} b_{21} h_{12, t-1}, \\
h_{22, t}= & w_{22}+a_{12}^{2} u_{1, t-1}^{2}+a_{22}^{2} u_{2, t-1}^{2}+2 a_{12} a_{22} u_{1, t-1} u_{2, t-1} \\
& +b_{12}^{2} h_{11, t-1}+b_{22}^{2} h_{22, t-1}+2 b_{12} b_{22} h_{12, t-1}, \\
h_{12, t}= & w_{12}+a_{11} a_{12} u_{1, t-1}^{2}+a_{21} a_{22} u_{2, t-1}^{2}+\left(a_{12} a_{21}+a_{11} a_{22}\right) u_{1, t-1} u_{2, t-1} \\
& +b_{11} b_{12} h_{11, t-1}+b_{21} b_{22} h_{22, t-1}+\left(b_{11} b_{22}+b_{12} b_{21}\right) h_{12, t-1} .
\end{aligned}
$$

Regarding the estimation of model (8), the parameters can be estimated by maximizing the log-likelihood function:

$$
l(\theta)=-\frac{T N}{2} \log 2 \pi-\frac{1}{2} \sum_{t=1}^{T}\left(\log \left|\mathbf{H}_{\mathbf{t}}\right|+\mathbf{\Xi}_{\mathbf{t}}^{\prime} \mathbf{H}_{\mathbf{t}}^{-1} \mathbf{\Xi}_{\mathbf{t}}\right)
$$

where $\theta$ denotes all of the unknown parameters to be estimated, $N$ is the number of assets, $T$ is the number of observations, and $\mathbf{H}_{\mathbf{t}}$ and $\boldsymbol{\Xi}_{t}$ are as defined earlier.

After deriving the time-varying covariances, $\operatorname{Cov}\left[r_{i, t}, r_{m, t} \mid \Omega_{t-1}\right]$ and $\operatorname{Cov}\left[r_{i, t}, \Delta c_{t} \mid \Omega_{t-1}\right]$, from the multivariate GARCH model, we first estimate regressions (4), (5), and (6) using monthly cross-sections. Then, the time-varying prices of risk $\delta_{t}$ and $\lambda_{t}$ can be evaluated monthly. Furthermore, to evaluate and compare the effectiveness of models (4), (5), and (6) by taking both the cross-sectional and the time-series aspects into account, we undertake panel data analysis. By pooling the monthly data on 25 size-ranked portfolios (size portfolios) and 25 $\mathrm{BE} / \mathrm{ME}-$ ranked portfolios (BE/ME portfolios), we can conduct a balanced panel data analysis in several time spans. The details of the empirical results are provided in Sections 6, 7, and 8. As above, in our context of testing three conditional asset pricing models, the use of the 
multivariate GARCH model enables us to implement the direct test of the time-varying risk pricing and the less restrictive test that no assumption is put on the state variable in the model conditioning, which is different from Shanken (1990), Ferson and Schadt (1996), or Lettau and Ludvigson (2001), for example. This is an advantage of our methodology in this paper (also see note 6).

\section{Data}

Our whole data sample period is from October 1981 to July 2004. We note that because of the data availability, this is the longest period to investigate as to Japan in our context. The individual data series are the risk-free percentage rate, $r_{f, t}$, the market portfolio percentage return, $r_{m, t}$, the growth rate in real per-capita seasonally adjusted private consumption, $\Delta c_{t}$, and $r_{i, t}$ is the returns of 25 portfolios constructed using the Tokyo Stock Exchange (TSE) First Section listed stocks.

More concretely, $r_{f, t}$ is the gensaki rate from the Japan Securities Dealers Association from October 1981 to May 1984 and the one-month median rate on negotiable-time certificates of deposit (CD) from the Bank of Japan from June 1984 to July 2004.(Note 11) The market return $r_{m, t}$ is the value-weighted return of all stocks in the TSE First Section from the Japan Securities Research Institute (JSRI). $\Delta c_{t}$ is constructed by dividing seasonally adjusted real consumption from the Government of Japan by the population estimates from the Ministry of Internal Affairs and Communications.

As $r_{i, t}$, we computed 25 value-weighted returns of size portfolios and 25 value-weighted returns of BE/ME portfolios, following Fama and French (1993). All TSE First Section listed stocks' return data from the JSRI are used to compute the portfolio returns.

\section{The Time-varying Risk Pricing}

This section examines the degree of the time-varying risk pricing of three asset pricing models. We also pay attention to the situation of the positiveness of the time-varying alphas in the conditional alpha CAPM.

\subsection{Portfolio Return Characteristics}

First, Table 1 presents sample statistics of the returns of the 25 size and BE/ME portfolios from October 1981 to July 2004. The mean returns of the size portfolios show a rather clear pattern of a monotonic increase from the largest to the smallest portfolio. The mean returns of the BE/ME portfolios also exhibit evidence of a monotonic increase, from the lowest to the highest $\mathrm{BE} / \mathrm{ME}$ portfolio, although the pattern is not as strong as that found in the size portfolios. Therefore, at this point, we find both a size effect and a BE/ME effect in Japan; however, the former seems to be stronger than the latter at the TSE First Section in Japan.

\subsection{The Time-varying Risk Pricing of the Conditional CAPM}

Applying equations (4), (5), and (6) to the cross-sectional data, we obtained the monthly time-varying risk prices.(Note 12) Figure 1 displays the monthly time-varying risk prices from the conditional CAPM of size portfolios for the period from January 1982 to December 
2003.(Note 13) Although not shown as tables,(Note 14) the monthly time-varying risk prices from the conditional CAPM were statistically significant in general; significant risk prices with theoretically consistent positive signs at the 5\% level equalled 135 of the 264 cases. Figure 2 also exhibits the monthly time-varying risk prices from the conditional CAPM for the $\mathrm{BE} / \mathrm{ME}$ portfolios. Again, the time-varying risk prices were generally statistically significant for the BE/ME portfolios; the number of significant risk prices with positive signs at the 5\% level equalled 123 of the 264 cases. The above results suggest that, from the viewpoint of risk pricing, in Japan, the conditional CAPM demonstrates better performance than the suggestions by Lewellen and Nagel (2006) and Fama and French (2006), amongst others.

\subsection{The Time-varying Risk Pricing and the Time-varying Alphas}

Next, Figures 3 and 5 present the monthly time-varying risk prices and time-varying alphas from the conditional alpha CAPM for the 25 size portfolios, respectively. Regarding the risk pricing, in general, the monthly time-varying risk prices for size portfolios were not statistically significant; in only 42 of 264 cases were the prices positive and significant at the $5 \%$ level. In contrast, the monthly time-varying alphas were positive and statistically significant at the 5\% level in 68 of 264 cases. Furthermore, there existed 152 cases of positive alphas, regardless of their statistical significance, in the 264 cases. Figures 4 and 6 display the monthly time-varying risk prices and alphas from the conditional alpha CAPM for BE/ME portfolios, respectively. Again, the time-varying risk prices were not statistically significant in the BE/ME portfolios; only 30 of 264 cases showed 5\% significance and positive signs. In contrast, the monthly time-varying alphas for the BE/ME portfolios were positive and statistically significant at the $5 \%$ level in 41 of 264 cases; this increased to 146 cases if all positive alphas were included regardless of statistical significance. Therefore, the application of the conditional alpha CAPM using the time-varying covariances from the multivariate GARCH model suggests that, as far as we can judge from our monthly analysis, positive alphas exist for Japan, although the alphas are not always statistically significant. It is also pointed out by Lewellen and Nagel (2006) and Fama and French (2006) that the effect of the alphas in evaluating the conditional asset pricing models is crucial, and this point is examined in more detail in Section 8.

\subsection{The Time-varying Risk Pricing of the Conditional CCAPM}

Figure 7 shows the monthly time-varying risk prices from the conditional CCAPM for the 25 size portfolios. In CCAPM, theoretically, the risk premium of an asset should be proportional to the covariance between the return of an asset and consumption growth (Mehra and Prescott (1985) and Mankiw and Zeldes (1991), amongst others). However, the number of statistically significant time-varying risk prices from the conditional CCAPM were far less than that from the conditional CAPM; the number of statistically significant risk prices with positive signs at the $5 \%$ level occurred in 54 of the 264 cases for the 25 size portfolios. Furthermore, Figure 8 depicts the monthly time-varying risk prices from the conditional CCAPM for the $25 \mathrm{BE} / \mathrm{ME}$ portfolios. Again, the number of statistically significant risk prices was much less than those in the conditional CAPM for the $25 \mathrm{BE} / \mathrm{ME}$ portfolios. Significant consumption risk prices 
with positive signs at the 5\% level occurred in 46 of the 264 cases. Therefore, for the traditional CCAPM, from the monthly risk pricing viewpoint, the conditional CCAPM is less supported than the conditional CAPM, even if the multivariate GARCH model is applied.

\section{Evaluation of the Conditional Asset Pricing Models}

This section attempts to more formally evaluate the empirical performance of three conditional asset pricing models. For the evaluation, we implement three types of formal $F$-tests on a monthly basis.(Note 15$)$ For the three $F$-tests, the tested period is from January 1982 to December 2003, the conditional time-varying covariances derived from the multivariate GARCH model are used, and the same data set of 25 size and BE/ME portfolios are again used.

Table 1. Sample statistics of the value-weighted returns on 25 portfolios formed on the basis of size and BE/ME: October 1981 to July 2004

\begin{tabular}{|c|c|c|c|c|c|c|c|c|c|}
\hline \multirow[b]{2}{*}{ Portfolio } & \multicolumn{4}{|c|}{ Size-ranked portfolios } & \multirow[b]{2}{*}{ Portfolio } & \multicolumn{4}{|c|}{ BE/ME-ranked portfolios } \\
\hline & Mean & Variance & Skewness & Kurtosis & & Mean & Variance & Skewness & Kurtosis \\
\hline Biggest & 0.880 & 34.806 & 0.334 & 0.826 & Highest & 2.032 & 69.049 & 0.571 & 2.107 \\
\hline Size 2 & 1.245 & 30.193 & 0.216 & 1.183 & $\mathrm{BE} / \mathrm{ME} 2$ & 1.838 & 45.395 & 0.147 & 1.006 \\
\hline Size 3 & 1.341 & 29.942 & 0.171 & 1.669 & BE/ME 3 & 1.861 & 45.686 & 0.267 & 1.718 \\
\hline Size 4 & 1.396 & 33.943 & -0.014 & 1.533 & $\mathrm{BE} / \mathrm{ME} 4$ & 1.746 & 48.948 & 0.608 & 1.510 \\
\hline Size 5 & 1.279 & 35.505 & 0.168 & 1.758 & BE/ME 5 & 1.707 & 48.172 & 0.548 & 0.863 \\
\hline Size 6 & 1.373 & 37.241 & 0.108 & 1.755 & BE/ME 6 & 1.778 & 42.823 & 0.144 & 0.609 \\
\hline Size 7 & 1.521 & 33.475 & 0.249 & 2.946 & $\mathrm{BE} / \mathrm{ME} 7$ & 1.950 & 44.786 & 0.246 & 0.447 \\
\hline Size 8 & 1.448 & 39.028 & 0.100 & 1.765 & BE/ME 8 & 1.550 & 44.244 & 0.442 & 1.332 \\
\hline Size 9 & 1.334 & 42.063 & 0.113 & 1.819 & BE/ME 9 & 1.537 & 40.285 & -0.013 & 0.814 \\
\hline Size 10 & 1.587 & 43.404 & 0.068 & 1.272 & $\mathrm{BE} / \mathrm{ME} 10$ & 1.881 & 45.487 & 0.350 & 1.349 \\
\hline Size 11 & 1.502 & 42.696 & 0.131 & 1.806 & $\mathrm{BE} / \mathrm{ME} 11$ & 1.719 & 39.362 & 0.500 & 0.983 \\
\hline Size 12 & 1.786 & 47.146 & 0.334 & 1.435 & $\mathrm{BE} / \mathrm{ME} 12$ & 1.207 & 35.977 & 0.098 & 1.588 \\
\hline Size 13 & 1.601 & 46.298 & 0.069 & 0.930 & $\mathrm{BE} / \mathrm{ME} 13$ & 1.600 & 38.687 & 0.408 & 1.601 \\
\hline Size 14 & 1.596 & 45.948 & 0.133 & 0.826 & BE/ME 14 & 1.308 & 36.352 & 0.219 & 0.980 \\
\hline Size 15 & 1.782 & 51.738 & 0.301 & 1.599 & $\mathrm{BE} / \mathrm{ME} 15$ & 1.297 & 33.159 & -0.021 & 0.740 \\
\hline Size 16 & 1.812 & 55.766 & 0.279 & 1.116 & $\mathrm{BE} / \mathrm{ME} 16$ & 1.288 & 34.835 & 0.406 & 2.994 \\
\hline Size 17 & 1.626 & 54.122 & 0.196 & 1.207 & BE/ME 17 & 1.350 & 39.235 & 0.748 & 4.757 \\
\hline Size 18 & 1.904 & 57.538 & 0.402 & 1.410 & BE/ME 18 & 1.153 & 38.323 & 0.605 & 3.220 \\
\hline Size 19 & 2.168 & 65.859 & 0.915 & 4.109 & BE/ME 19 & 1.045 & 37.947 & 0.708 & 2.993 \\
\hline Size 20 & 1.719 & 58.811 & 0.522 & 2.349 & $\mathrm{BE} / \mathrm{ME} 20$ & 1.001 & 33.143 & 0.314 & 1.585 \\
\hline Size 21 & 2.170 & 61.365 & 0.309 & 0.967 & $\mathrm{BE} / \mathrm{ME} 21$ & 1.079 & 41.158 & 0.467 & 2.477 \\
\hline Size 22 & 2.092 & 66.998 & 0.302 & 1.645 & $\mathrm{BE} / \mathrm{ME} 22$ & 1.117 & 41.062 & 0.344 & 1.337 \\
\hline Size 23 & 2.546 & 72.813 & 0.400 & 0.588 & $\mathrm{BE} / \mathrm{ME} 23$ & 0.811 & 42.155 & 0.562 & 2.689 \\
\hline Size 24 & 2.775 & 80.312 & 0.596 & 1.847 & $\mathrm{BE} / \mathrm{ME} 24$ & 0.565 & 43.652 & 0.182 & 1.171 \\
\hline Smallest & 3.762 & 111.198 & 1.055 & 2.935 & Lowest & 0.545 & 47.542 & 0.105 & 2.233 \\
\hline
\end{tabular}

Note: The sample statistics of the value-weighted returns of 25 portfolios formed on the basis of size or BE/ME (book equity to market equity) ratios are displayed. The sample period is from October 1981 to July 2004. The size- and BE/ME-ranked portfolios are constructed following Fama and French (1993). In constructing the size-ranked portfolios, TSE (Tokyo Stock Exchange) First Section stocks were allocated to one of 25 groups based on their market equity (ME, stock price times shares outstanding) at the end of September of each year $t$ (1981-2003). Value-weighted monthly returns on the 25 portfolios were then calculated from the following October to the next September. When constructing the BE/ME portfolios, the BE/ME ratio used to form the portfolios in September of year $t$ is the book common equity for the fiscal year $t-1$, divided by the market equity at the end of March in calendar year $t$. Negative BE firms were not used in forming the BE/ME portfolios. The value-weighted monthly returns on the portfolios are then calculated from October to the following September like the size-ranked portfolios. Only firms with ordinary common equity are included. REITs (Real Estate Investment Trusts) and units of beneficial interest are excluded. 


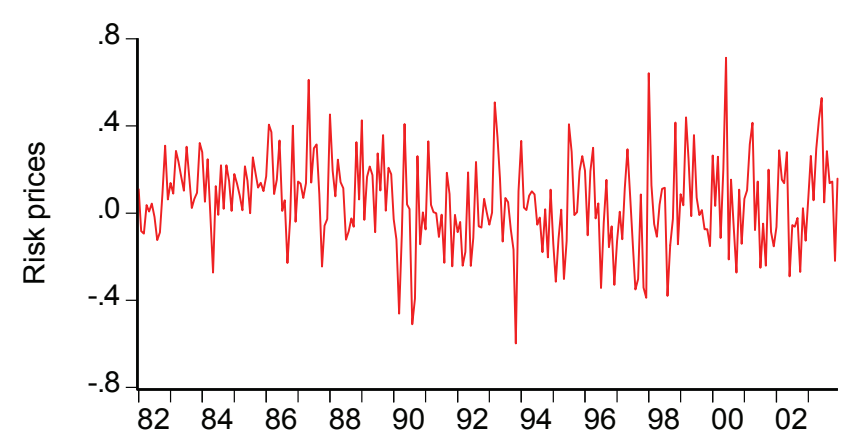

Figure 1. Time-varying risk prices of the conditional CAPM from size portfolios

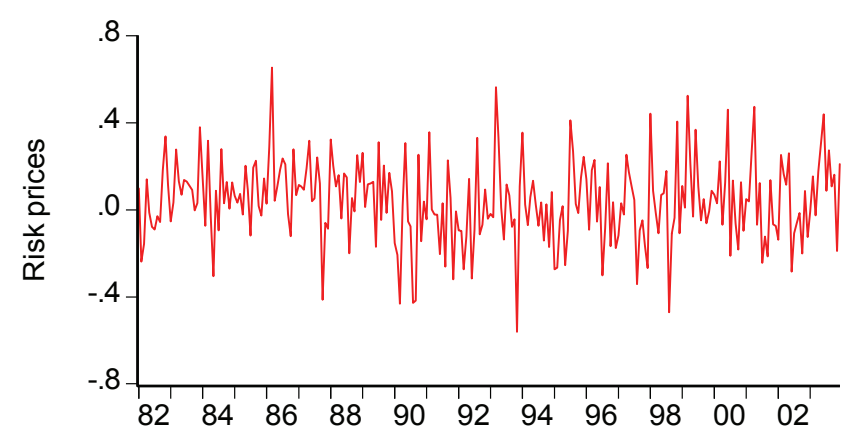

Figure 2. Time-varying risk prices of the conditional CAPM from BE/ME portfolios

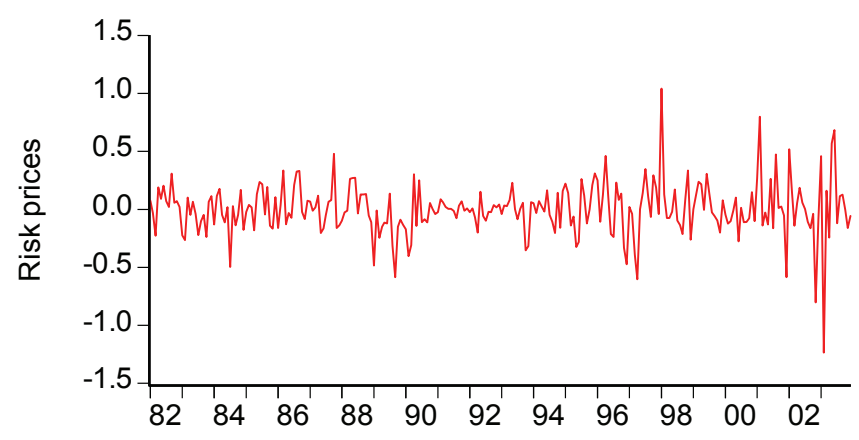

Figure 3. Time-varying risk prices of the conditional alpha CAPM from size portfolios

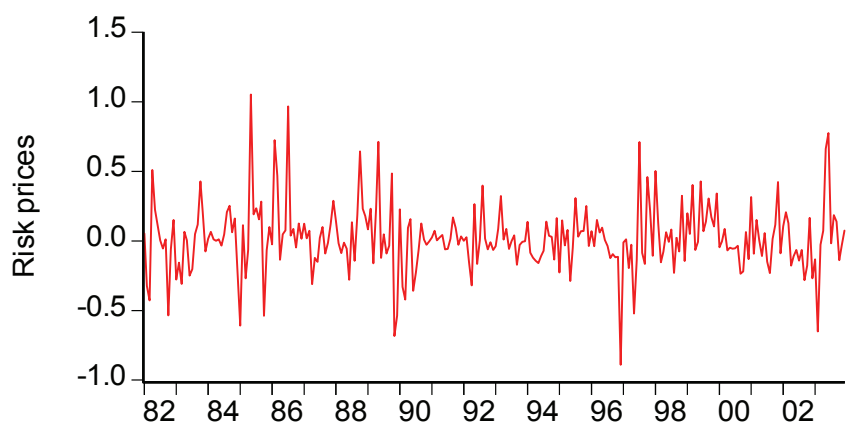

Figure 4. Time-varying risk prices of the conditional alpha CAPM from BE/ME portfolios 


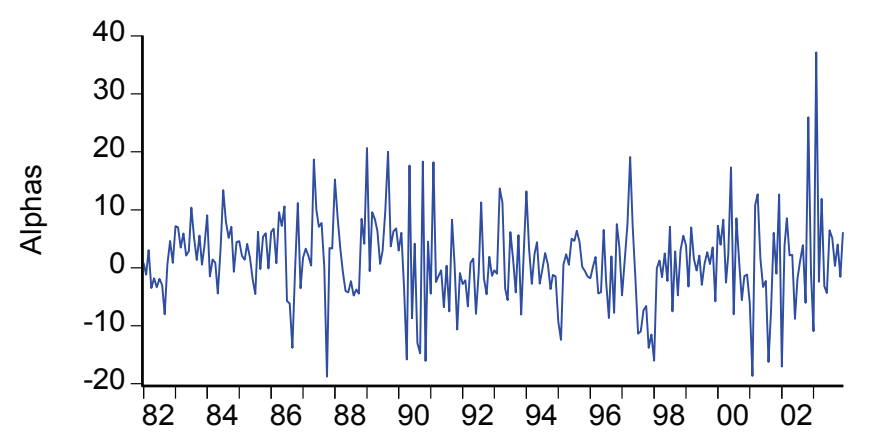

Figure 5. Time-varying alphas of alpha CAPM from size portfolios

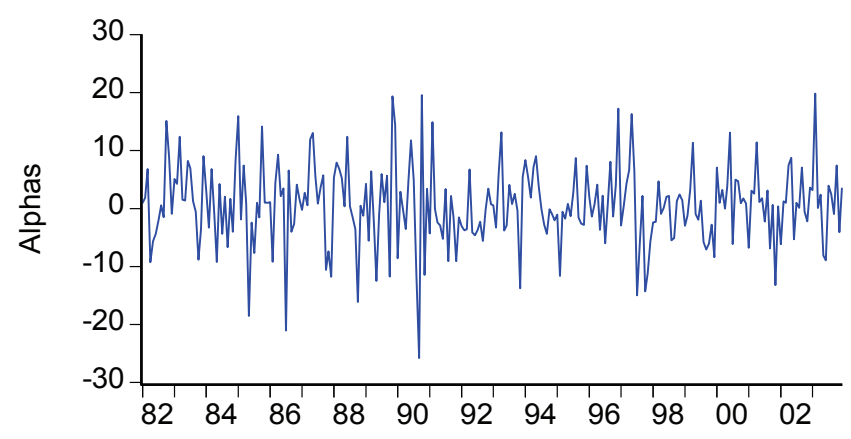

Figure 6. Time-varying alphas of alpha CAPM from BE/ME portfolios

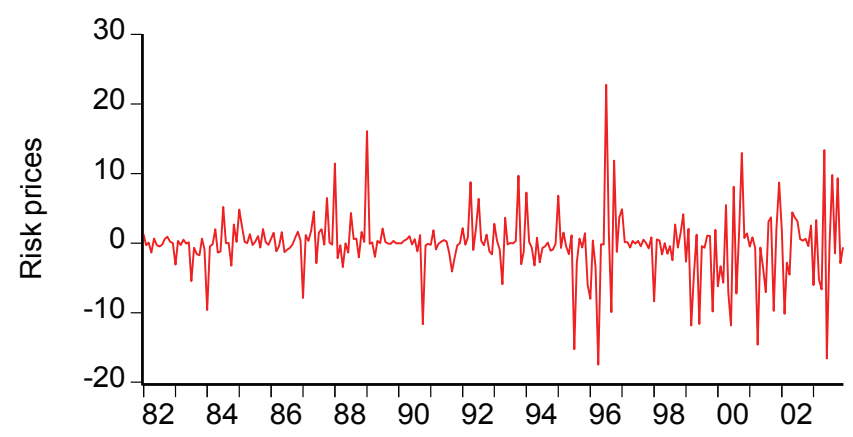

Figure 7. Time-varying risk prices of the conditional CCAPM from size portfolios

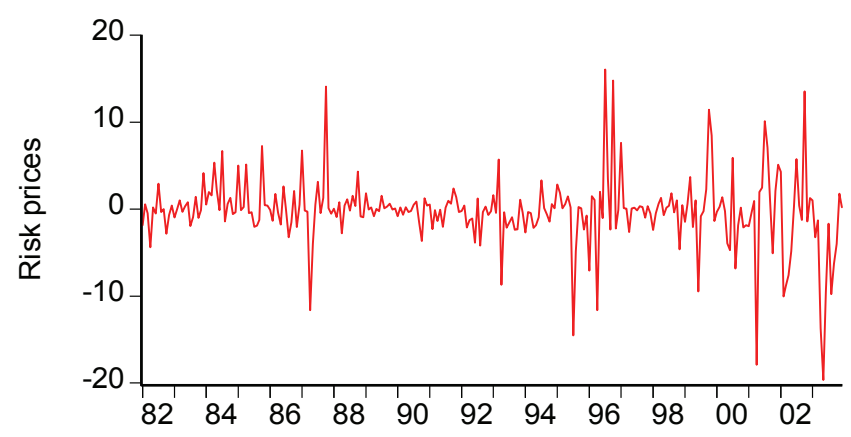

Figure 8. Time-varying risk prices of the conditional CCAPM from BE/ME portfolios 


\subsection{The Conditional CAPM versus the Conditional CCAPM}

The first test procedure is as follows. Because the conditional CAPM (4) and the conditional CCAPM (6) are non-nested models of each other, following Maddala (1992), we combine the two models as the following model (13):

$$
E\left[\left(r_{i, t}-r_{f, t}\right) \mid \Omega_{t-1}\right]=\delta_{t} \operatorname{Cov}\left[r_{i, t}, r_{m, t} \mid \Omega_{t-1}\right]+\lambda_{t} \operatorname{Cov}\left[r_{i, t}, \Delta c_{t} \mid \Omega_{t-1}\right]
$$

By using model (13), we implement the first monthly $F$-test. In model (13), the null hypothesis is $H_{0}: \lambda_{t}=0$ and the alternative hypothesis is $H_{1}: \delta_{t}=0$. Under $H_{0}$ and $H_{1}$, the $F$-statistic (14) follows an $F$-distribution with $r$ and $n-k$ degrees of freedom.

$$
F_{\text {Test } 1}=\frac{(R R S S-U R S S) / r}{U R S S /(n-k)} .
$$

RRSS is the sum of squared residuals of the restricted model (4) or (6),(Note 16) URSS is the sum of squared residuals of the unrestricted model (13), $r$ is the number of restrictions, $n$ is the number of samples, and $k$ is the number of explanatory variables in the unrestricted model (13). In the model evaluation, when $H_{0}$ is not rejected, the conditional CAPM is supported, whilst when $H_{1}$ is not rejected, the conditional CCAPM is supported.(Note 17)

Regarding the first test, Table 2 shows the results for the conditional CAPM versus the conditional CCAPM in the case of the 25 size portfolios. In Table $2, H_{0}$ is rejected in 40 of 264 cases, whilst $H_{1}$ is rejected in 218 of 264 cases. Therefore, in this first monthly $F$-test, out of 264 cases, the conditional CAPM is rejected only 40 times, while the conditional CCAPM is rejected in 218 cases. Hence, the evidence implies that the conditional CAPM is, by far, superior to the conditional CCAPM for the 25 size portfolios in Japan. Furthermore, Table 3 displays the results of the first $F$-test for the $25 \mathrm{BE} / \mathrm{ME}$ portfolios. The table indicates that $H_{0}$ is rejected in 19 of 264 cases, whilst $H_{1}$ is rejected 214 times. Therefore, the results suggest that out of 264 cases, the conditional CAPM is rejected only 19 times, whilst the conditional CCAPM is rejected in 214 cases. Thus, we can judge that again, the conditional CAPM outperforms the conditional CCAPM in the case of the $25 \mathrm{BE} / \mathrm{ME}$ portfolios in Japan.

\subsection{The Conditional Alpha CAPM Versus the Conditional CCAPM}

As for the second test procedure, the conditional alpha CAPM (5) and the conditional CCAPM (6) are again non-nested models of each other. Thus, again following Maddala (1992), we combine the two models as model (15):

$$
E\left[\left(r_{i, t}-r_{f, t}\right) \mid \Omega_{t-1}\right]=\alpha_{t}+\delta_{t} \operatorname{Cov}\left[r_{i, t}, r_{m, t} \mid \Omega_{t-1}\right]+\lambda_{t} \operatorname{Cov}\left[r_{i, t}, \Delta c_{t} \mid \Omega_{t-1}\right]
$$

By exploiting this model (15), we implement the second monthly $F$-test. In model (15), the null hypothesis is $H_{0}: \lambda_{t}=0$ and the alternative hypothesis is $H_{1}: \alpha_{t}=0$ and $\delta_{t}=0$. Under $H_{0}$ and $H_{1}$, the $F$-statistic (16) follows the $F$-distribution, whose degrees of freedom are $r$ and $n$ $-k-1$. 


$$
F_{\text {Test } 2,3}=\frac{(R R S S-U R S S) / r}{U R S S /(n-k-1)} .
$$

RRSS is the sum of squared residuals of the restricted model (5) or (6),(Note 18) URSS is the sum of squared residuals of the unrestricted model (15), $r$ and $n$ are the same as in (14), and $k$ is the number of explanatory variables in the unrestricted model (15).

When $H_{0}$ is not rejected, the conditional alpha CAPM is supported, whilst when $H_{1}$ is not rejected, the conditional CCAPM is supported.(Note 19)

Table 4 shows the second $F$-test results; the conditional alpha CAPM versus the conditional CCAPM in the case of the 25 size portfolios. In Table $4, H_{0}$ is rejected in 31 of 264 cases, whilst $H_{1}$ is rejected in 222 of 264 cases. Therefore, out of 264 cases, the conditional alpha CAPM is rejected only 31 times, while the conditional CCAPM is rejected in 222 cases. Hence, we understand that the conditional alpha CAPM outperforms the conditional CCAPM in the case of the 25 size portfolios in Japan. Furthermore, Table 5 exhibits the second $F$-test results for the $25 \mathrm{BE} / \mathrm{ME}$ portfolios. In the table, $H_{0}$ is rejected in 16 of 264 cases, whilst $H_{1}$ is rejected in 211 of 264 cases. The results mean that out of 264 cases, the conditional alpha CAPM is rejected only 16 times, whilst the conditional CCAPM is rejected in 211 cases. Therefore, we can conclude that in Japan, the conditional alpha CAPM is by far superior to the conditional CCAPM in the case of the $25 \mathrm{BE} / \mathrm{ME}$ portfolios as well.

\subsection{The Conditional CAPM versus the Conditional Alpha CAPM}

Regarding our third test, the conditional CAPM (4) is a nested model of the conditional alpha CAPM (5); therefore, by setting a restriction on the conditional alpha CAPM (5), we can implement the third monthly $F$-test. Namely, in model (5), we set the null hypothesis as $H_{0}: \alpha_{t}$ $=0$ and set the alternative hypothesis as $H_{1}: \alpha_{t} \neq 0$. Under $H_{0}$, the above mentioned $F$-statistic (16) follows an $F$-distribution with $r$ and $n-k-1$ degrees of freedom as in the second test. RRSS is the sum of squared residuals of the restricted model (4), URSS is the sum of squared residuals of the unrestricted model (5), $r$ and $n$ are the same as in (14), and $k$ is the number of explanatory variables in the unrestricted model (5).

Here, when $H_{0}$ is rejected, the conditional CAPM is rejected and the conditional alpha CAPM is supported, whilst when $H_{0}$ is not rejected, the conditional CAPM is supported and the conditional alpha CAPM is rejected.

Table 6 shows the third $F$-test results; the conditional CAPM versus the conditional alpha CAPM in the case of the 25 size portfolios. In Table $6, H_{0}$ is rejected in 109 of 264 cases; this means that out of 264 cases, the conditional CAPM is rejected against the conditional alpha CAPM 109 times (the rejection rate is $41.3 \%$ ). Hence, we conclude that the conditional CAPM is slightly better than the conditional alpha CAPM in the case of the 25 size portfolios in Japan. Furthermore, Table 7 displays the third test results for the $25 \mathrm{BE} / \mathrm{ME}$ portfolios. The table indicates that $H_{0}$ is rejected in 74 of 264 cases, and this means that out of 264 cases, the conditional CAPM is rejected against the conditional alpha CAPM only 74 times (the rejection rate is $28.0 \%$ ). Hence, we conclude that the conditional CAPM is clearly superior to 
the conditional alpha CAPM in the case of the 25 BE/ME portfolios in Japan.

\section{Comparisons and Discussions with Other Studies}

Finally, based on the arguments of other existing influential studies, such as Chen et al. (1986), Lewellen and Nagel (2006), Fama and French (1996, 2006), Lettau and Ludvigson (2001), amongst others, we conduct additional tests and discussions below. These tests are also worthwhile for checking the robustness of our previous results.

The most critical issues regarding the conditional asset pricing models argued by Lewellen and Nagel (2006) are that 1) the conditioning methods using observable variables, seen in existing works such as Harvey (1989), Shanken (1990), Jagannathan and Wang (1996), Lettau and Ludvigson (2001), amongst others, limit the information set; therefore, through such a conditioning method, we can only test the implications conditioned by several observable variables; 2) the main focus of most existing studies is cross-sectional regressions; thus, they ignore time-series characteristics; and 3) the direct test of the conditional CAPM is to examine whether the conditional alphas are zero.

Regarding the first point, because we use the multivariate GARCH model, which enables us to derive the conditional covariances for tests without using any state variables, our research is not subject to this critique. Therefore, below, we only discuss the latter two points. As to the second point, to further evaluate our three conditional models by taking into consideration both the time-series and the cross-sectional aspects, we perform a balanced panel data analysis. Furthermore, as for the third point, we additionally test the conditional alphas, as suggested by Lewellen and Nagel (2006) and Fama and French (2006).

\subsection{Panel Data Analysis}

First, Table 8 displays the results of the pooled regressions for the entire sample period from October 1981 to July 2004 and for four subsample periods. Table 8 indicates that the risk price from the conditional CAPM is statistically significant for all testing periods and for both the size and the BE/ME portfolios, with only one exception in the case of the BE/ME portfolios over the subperiod from January 1987 to December 1992. For example, Chen et al. (1986) show that the unconditional CAPM pricing is weakly statistically significant in the entire period of 1958-1984 and in only one subperiod of 1978-1984 in the cases of 20 size-ranked portfolios (Chen et al. (1986), Table 5, p. 398). Therefore, we suggest that the statement "the conditional CAPM performs nearly as poorly as the unconditional CAPM" (Lewellen and Nagel 2006, p. 291) does not hold in the case of Japan.

In contrast to this result, Table 8 also shows that the risk price from the conditional CCAPM is never statistically significant with the theoretically consistent positive sign. Once again, the conditional CCAPM is not supported from the viewpoint of risk pricing in Japan.(Note 20)

Furthermore, regarding the conditional alpha CAPM, the intercepts, the alphas, are statistically significant with positive signs in seven of 10 cases; thus, we need more formal tests especially for the conditional CAPM versus the conditional alpha CAPM using the panel data. Thus, we again perform the three types of formal tests by using panel data below. 


\subsubsection{The Conditional CAPM Versus the Conditional CCAPM}

The first test using the panel data is the conditional CAPM versus the conditional CCAPM. The null hypothesis is $H_{0}: \lambda_{t}=0$ and the alternative hypothesis is $H_{1}: \delta_{t}=0$ in model (13). As before, under $H_{0}$ (the conditional CAPM holds) and $H_{1}$ (the conditional CCAPM holds), the $F$-statistic (17) follows an $F$-distribution with $r$ and $n T-k$ degrees of freedom.(Note 21)

$$
F_{\text {Test } 1}^{\text {Panel }}=\frac{(R R S S-U R S S) / r}{U R S S /(n T-k)} .
$$

The left section of Table 9 shows the results for the 25 size portfolios in Panel A and for the $25 \mathrm{BE} / \mathrm{ME}$ portfolios in Panel B. In Table $9, H_{0}$ is never rejected in all 10 cases in Panels A and $\mathrm{B}$; this means that, in this first panel $F$-test, in all 10 cases, the conditional CAPM is never rejected for the panel data. However, $H_{1}$ (CCAPM holds) is rejected in six out of 10 cases in Panels A and B, and the six rejection cases include the entire sample period cases for both the size and the BE/ME portfolios. Therefore, as with the monthly results, we conclude that, for the panel data, the conditional CAPM is again superior to the conditional CCAPM in Japan.

\subsubsection{The Conditional Alpha CAPM Versus the Conditional CCAPM}

In the second additional panel data test, the null hypothesis is $H_{0}: \lambda_{t}=0$ and the alternative hypothesis is $H_{1}: \alpha_{t}=0$ and $\delta_{t}=0$ in model (15). Under $H_{0}$ (the conditional alpha CAPM holds) and $H_{1}$ (the conditional CCAPM holds), the $F$-statistic (18) follows the $F$-distribution whose degrees of freedom are $r$ and $n T-k-n$.(Note 22)

$$
F_{\text {Test } 2,3}^{\text {Panel }}=\frac{(R R S S-U R S S) / r}{U R S S /(n T-k-n)} .
$$

The middle section of Table 9 displays the results for the 25 size portfolios in Panel A and for the $25 \mathrm{BE} / \mathrm{ME}$ portfolios in Panel B. The table indicates that $H_{0}$ is not rejected for all 10 cases in Panels A and B. Therefore, this second panel $F$-test suggests that in all 10 cases, the conditional alpha CAPM is never rejected. On the other hand, it is shown that $H_{1}$ (CCAPM holds) is rejected eight out of 10 times in Panels A and B; the rejection cases are seen in the entire sample period analysis for both the size and the BE/ME portfolios. Therefore, from this second panel $F$-test, we understand, again like the results of the monthly tests, that the conditional alpha CAPM outperforms the traditional conditional CCAPM in Japan.

\subsubsection{The Conditional Alpha CAPM versus the Conditional CAPM}

The third additional panel data test is the conditional alpha CAPM versus the conditional CAPM. In model (5), as before, we set the null hypothesis as $H_{0}: \alpha_{t}=0$ and the alternative hypothesis as $H_{1}: \alpha_{t} \neq 0$. Under $H_{0}$ (the conditional CAPM holds), the $F$-statistic (18) follows an $F$-distribution with $r$ and $n T-k-n$ degrees of freedom.(Note 23)

The right section of Table 9 displays the results for the 25 size portfolios in Panel A and the 
results for the $25 \mathrm{BE} / \mathrm{ME}$ portfolios in Panel B. The table indicates that, in Panel A, $H_{0}$ is rejected in three of the five cases, and these three cases involve the entire sample period test case. In Panel B, $H_{0}$ is never rejected in the five cases. Therefore, this third additional panel $F$-test demonstrates that, in the case of the size portfolios, in all five cases, the conditional CAPM is supported in only two subperiod cases. However, contrary to this, in the BE/ME portfolios, the conditional CAPM is supported against the conditional alpha CAPM in all five cases in Japan. We note that the above results for the BE/ME portfolios are consistent with the results of Ang and Chen (2007), who insist that the CAPM can explain US value premiums from 1926 to 1963, and are inconsistent with the suggestion of Fama and French $(1996,2006)$ that the CAPM cannot explain the value premiums in the US.(Note 24)

\subsection{Testing the Time-varying Alpha}

Finally, we move to the third sceptical view of conditioning by Lewellen and Nagel (2006): the test of the conditional alphas is essential for judging the validity of the conditional CAPM. To investigate this matter in Japan, we further test the time-varying alphas derived from our previous analysis. We also consider that this test serves as a robustness check of our previous results between the conditional CAPM and the conditional alpha CAPM.

Regarding the test, more precisely, using the average values of the time-varying alphas exhibited in Figures 5 and 6, we implement the following $t$-test for the entire sample period from January 1982 to December 2003 and for four subperiods. The null hypothesis is $H_{0}$ : $\operatorname{Avg}\left[\alpha_{t}\right]=\mu_{0}=0$, and the alternative hypothesis is $H_{1}: \operatorname{Avg}\left[\alpha_{t}\right] \neq 0$, where $\operatorname{Avg}\left[\alpha_{t}\right]$ is the average value of the time-series alphas.(Note 25) The test $t$-statistic is $T=\left[\bar{\alpha}-\mu_{0}\right] /[s / \sqrt{n}]$, where $\bar{\alpha}$ is the sample average of the time-varying alphas, $\mu_{0}=0$ under the null hypothesis, $s$ is the standard deviation of the time-varying alphas, and $n$ is the number of samples. Under $H_{0}$, $T=\left[\bar{\alpha}-\mu_{0}\right] /[s / \sqrt{n}]$ follows a $t$-distribution with $n-1$ degrees of freedom. Thus, in the test, if $|T|>t_{p / 200}(n-1), H_{0}$ is rejected at the $p \%$ significance level, where $t_{k}(n-1)$ denotes the $100 k \%$ point value of the $t$-distribution, with $n^{-1}$ degrees of freedom.

Panel A of Table 10 shows the results for the 25 size portfolios, while Panel B displays the results for the $25 \mathrm{BE} / \mathrm{ME}$ portfolios. Panel A shows that for three out of five cases, the null hypothesis $H_{0}: \operatorname{Avg}\left[\alpha_{t}\right]=0$ is supported; however, the two rejections involve the entire sample period test case. On the other hand, in Panel B of Table 10, it is demonstrated that in all five cases, the null $H_{0}$ is not rejected. Therefore, from the viewpoint of the conditional alphas, the conditional CAPM is supported in explaining the value effect in Japan, although it is again of limited effectiveness in explaining the size effect in Japan. 


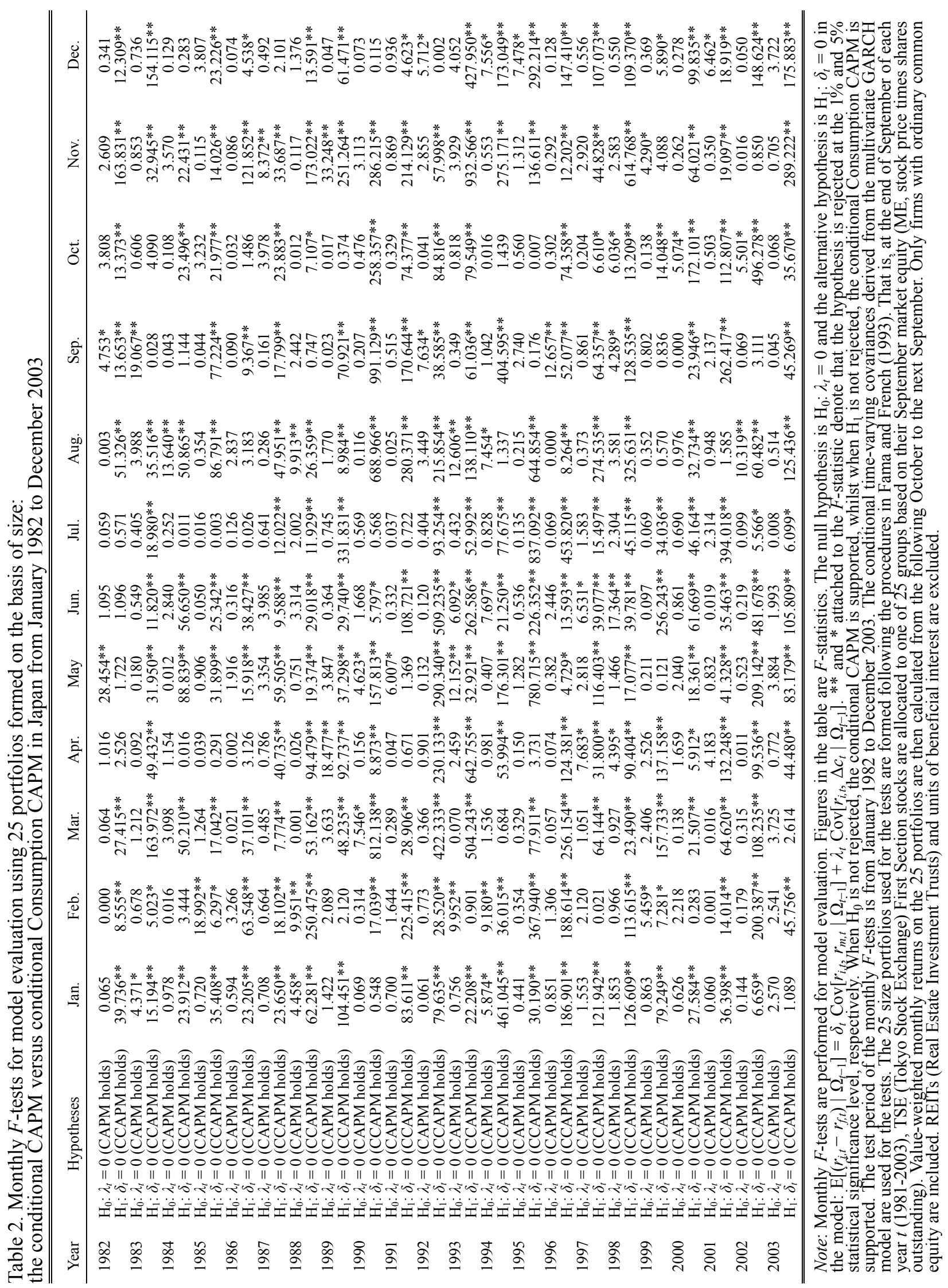




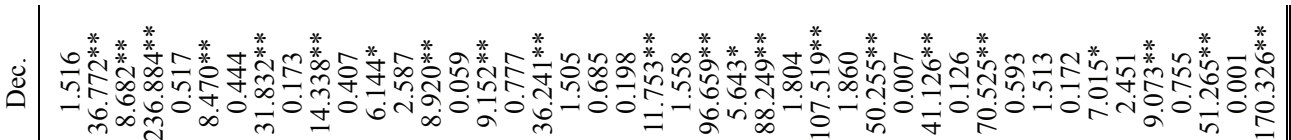

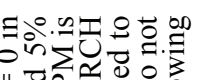

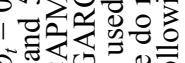
1.0.

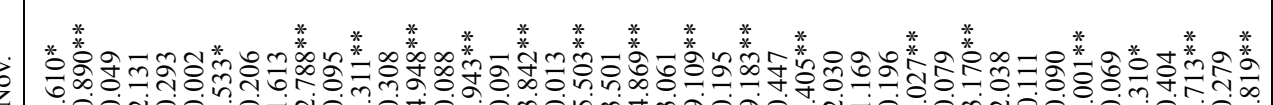

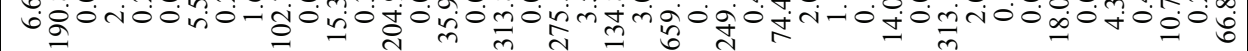

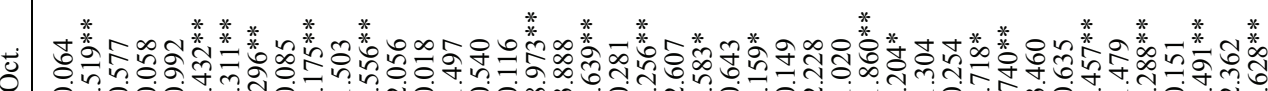

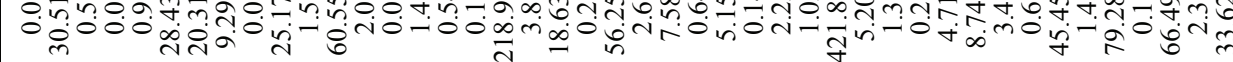

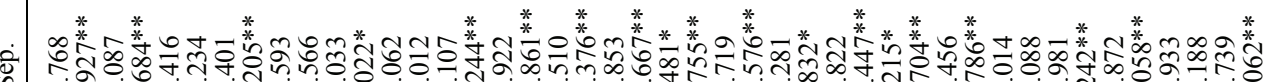

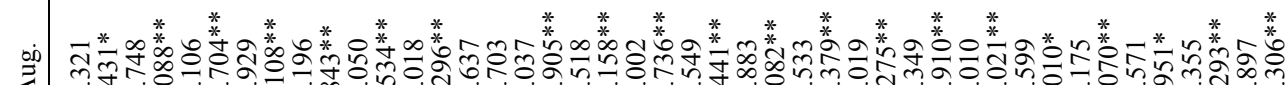

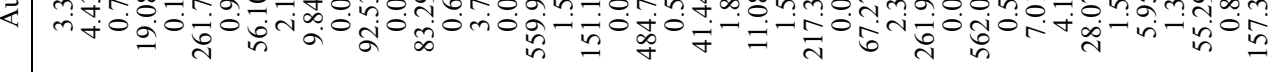

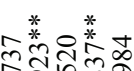

nis

* * * * * * * * *

*

* * * * * * * *

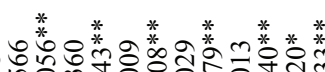

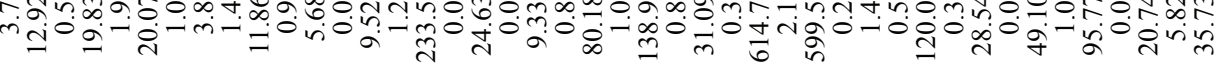

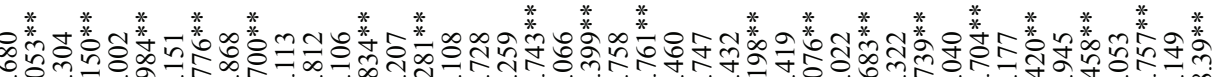

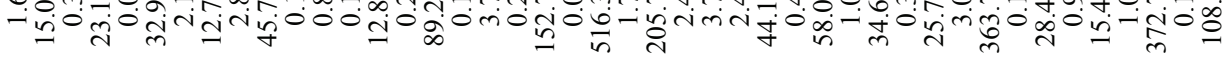

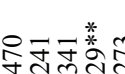

$8 *$ *

* * *

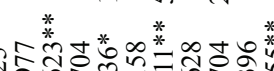

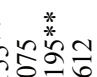

若

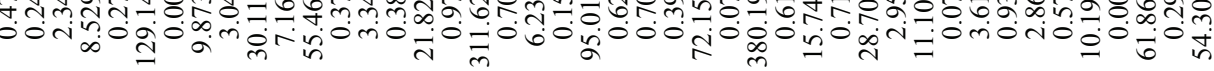

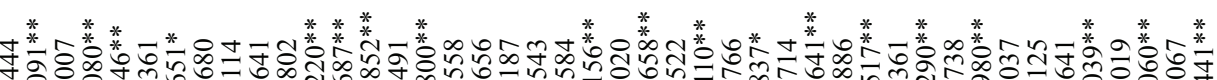
ते फू.

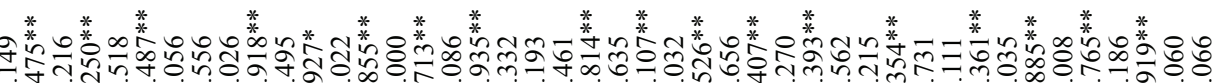

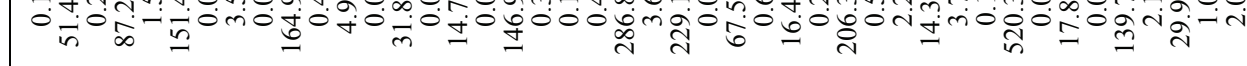

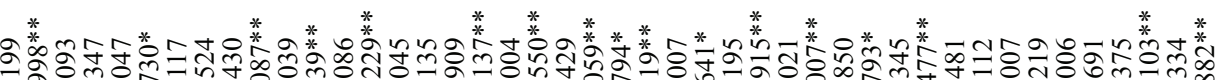
ठ্

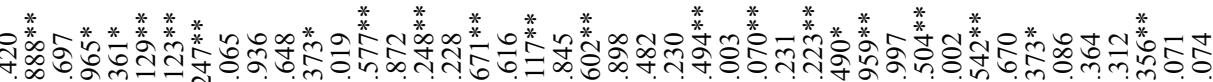

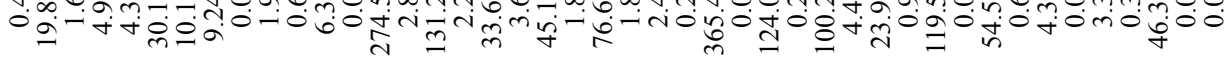
吾

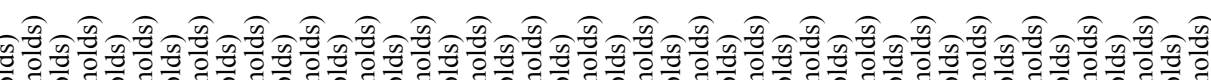

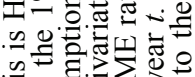

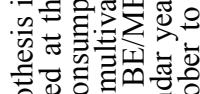

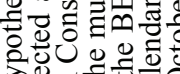
2. . त.

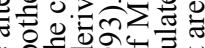

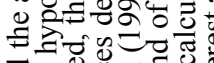
它承

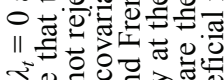

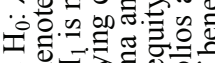
. क. 氙 $\Rightarrow 3$.

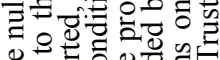

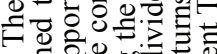
मे 矛过

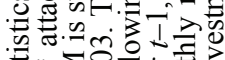

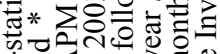

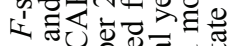
* * 즐

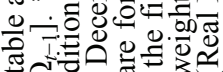

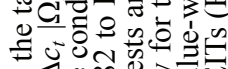

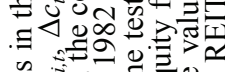

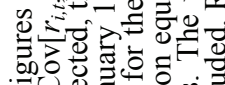

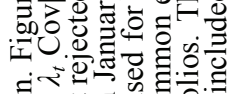

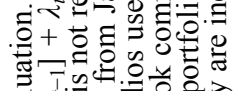

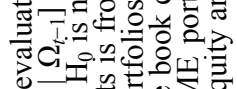

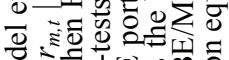

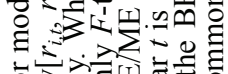

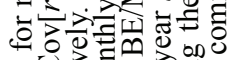
o.

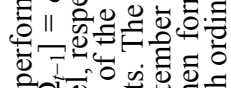

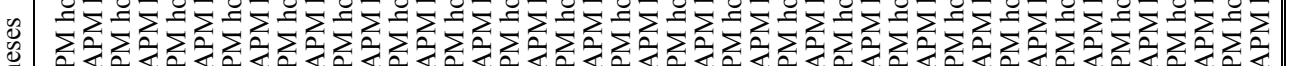

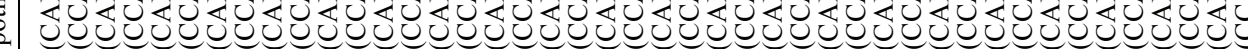
年 || || || || || || || || || || || || || || || || || || || || || || || || || || || || || || || || || || || || || || ||

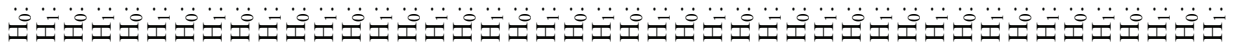




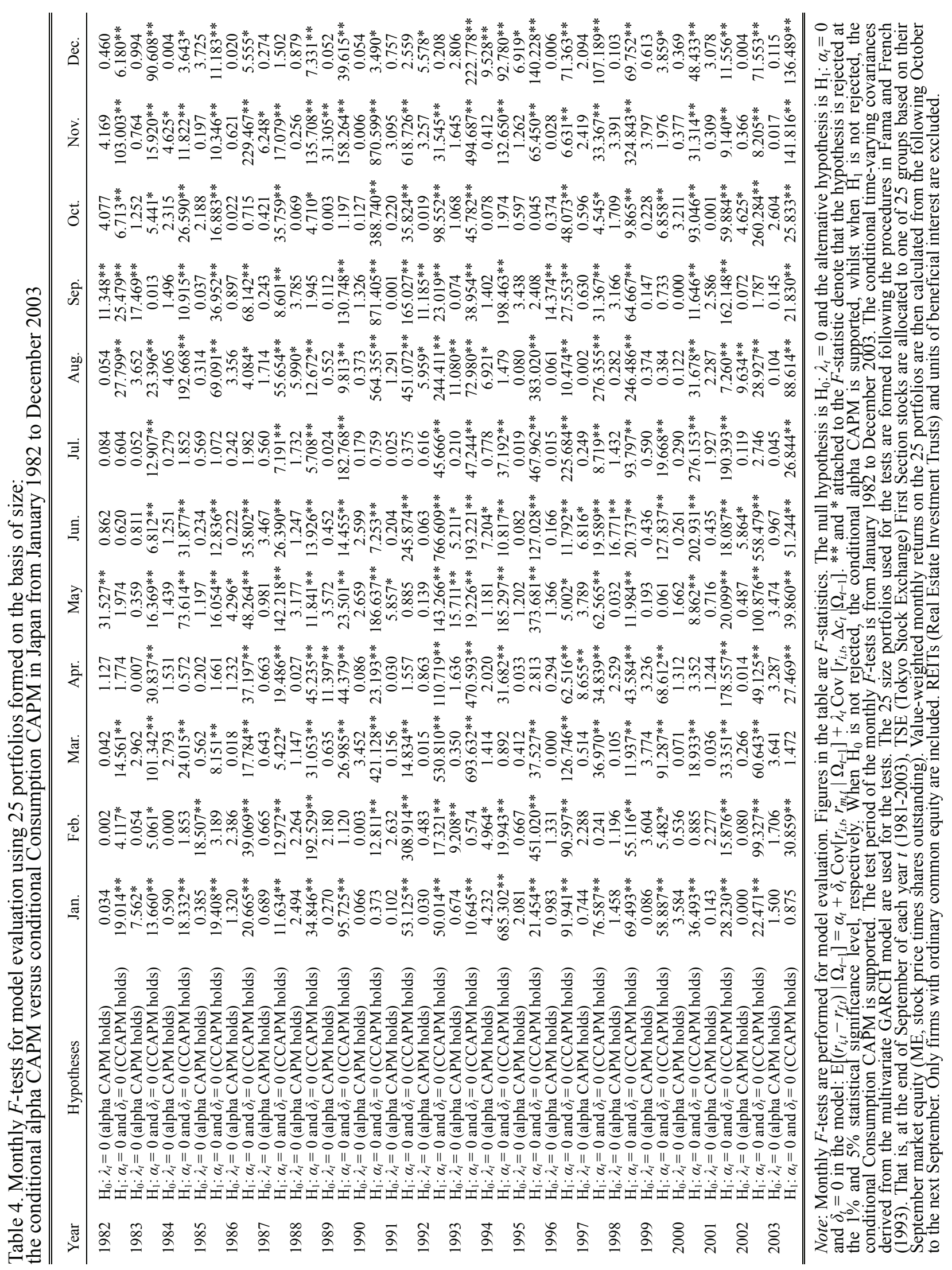




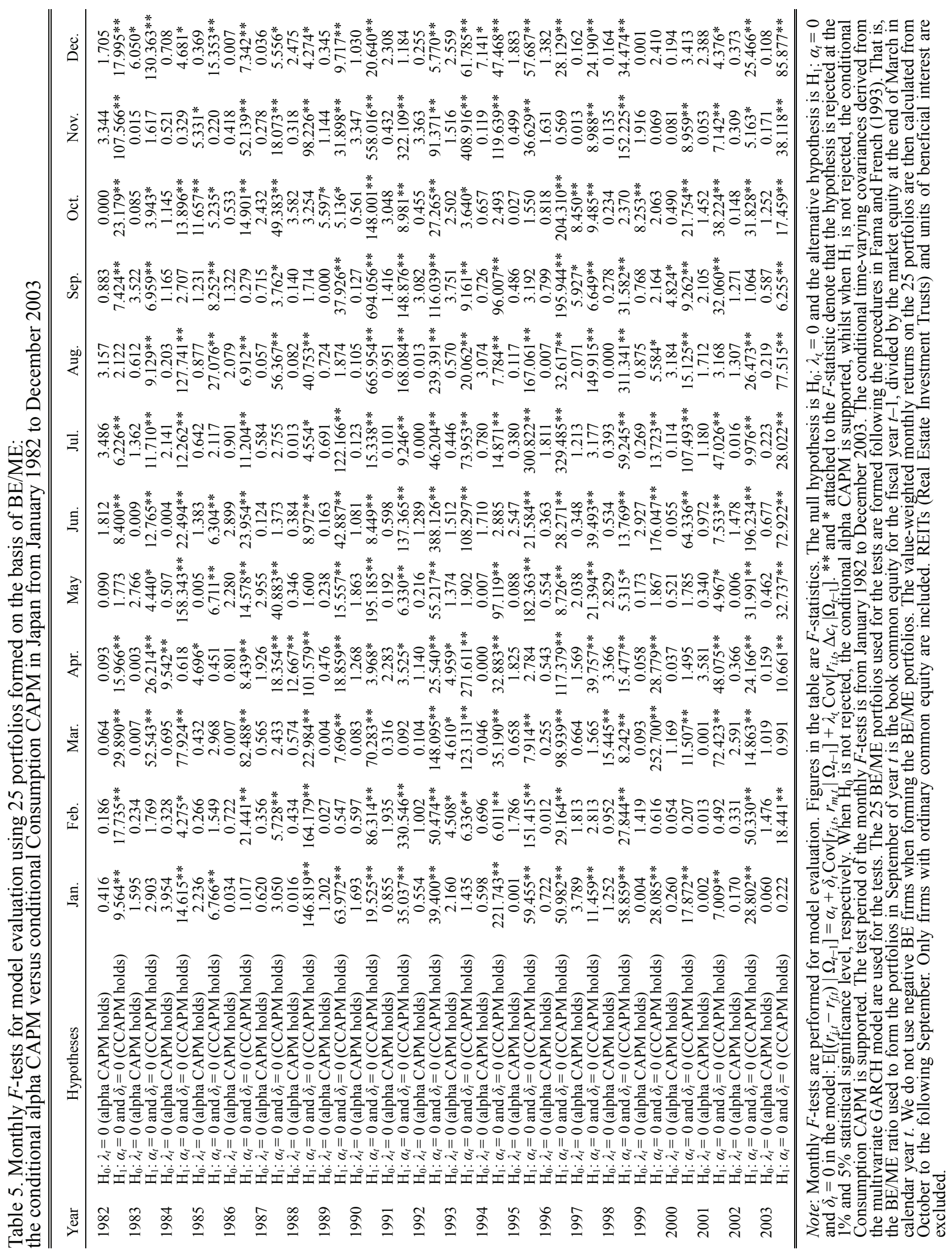




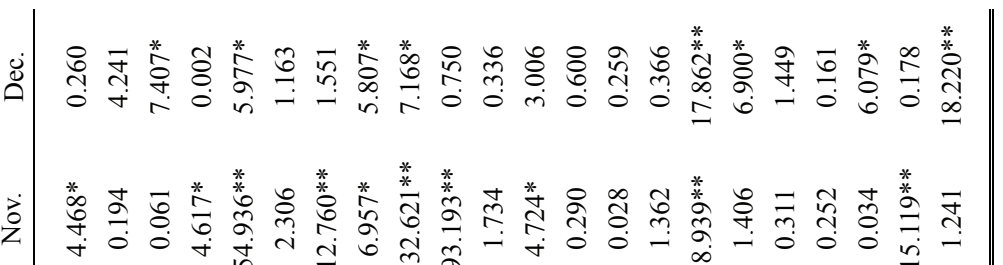

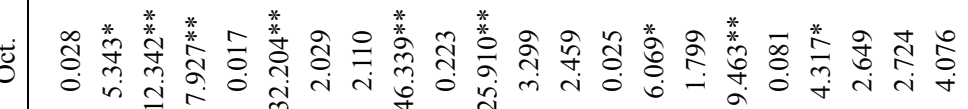

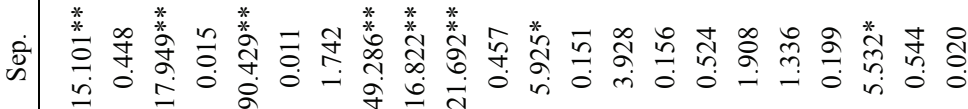

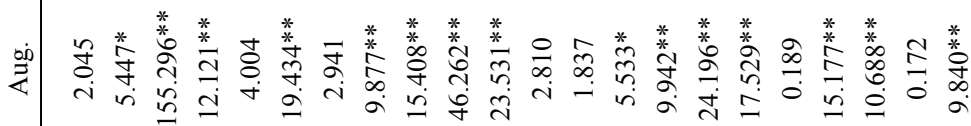

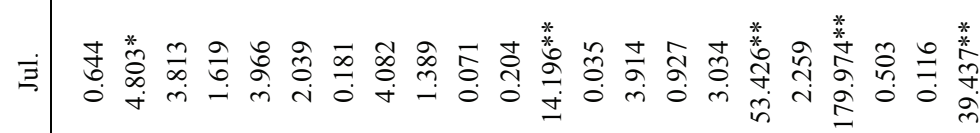

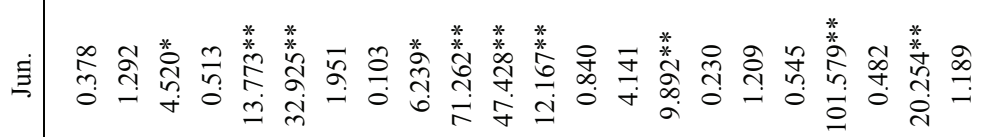

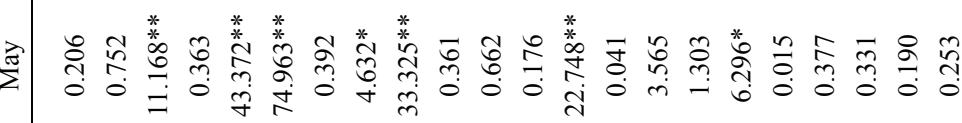

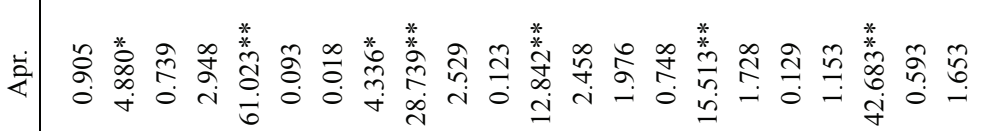

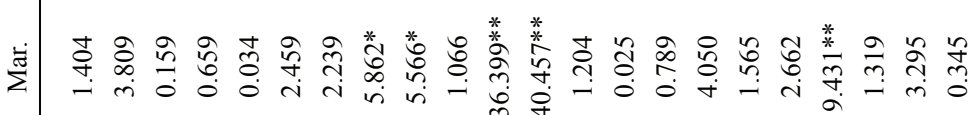

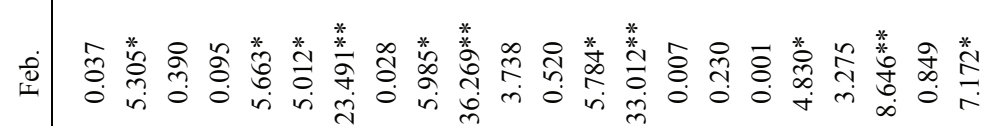

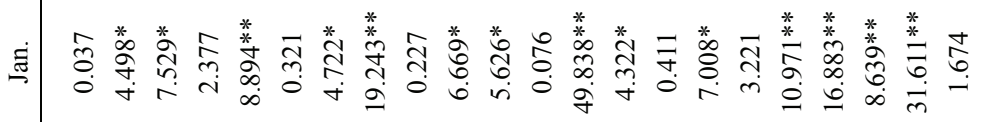

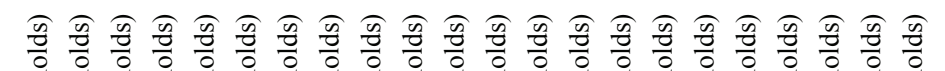

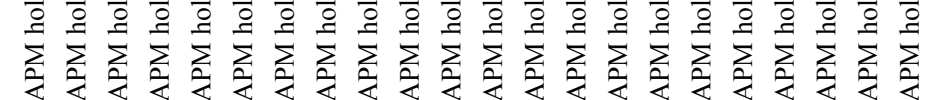

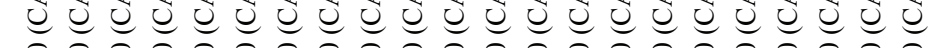

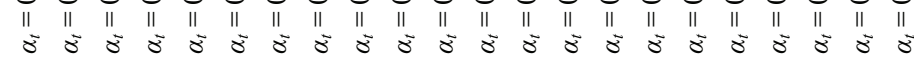

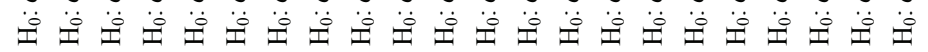

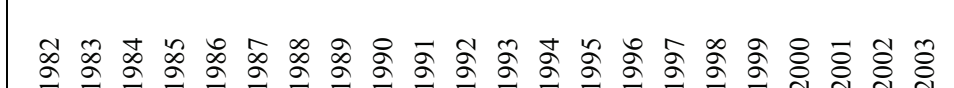

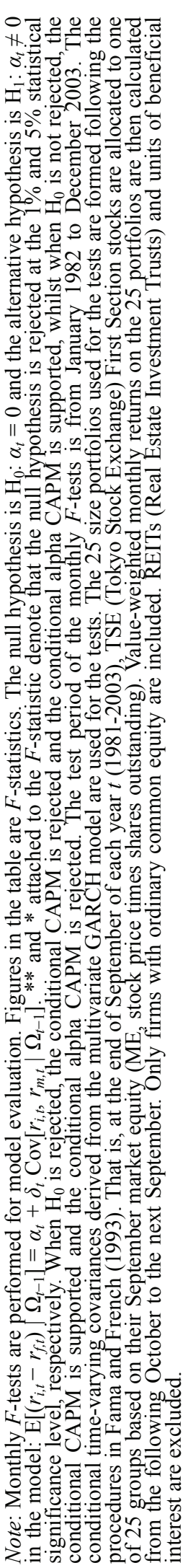




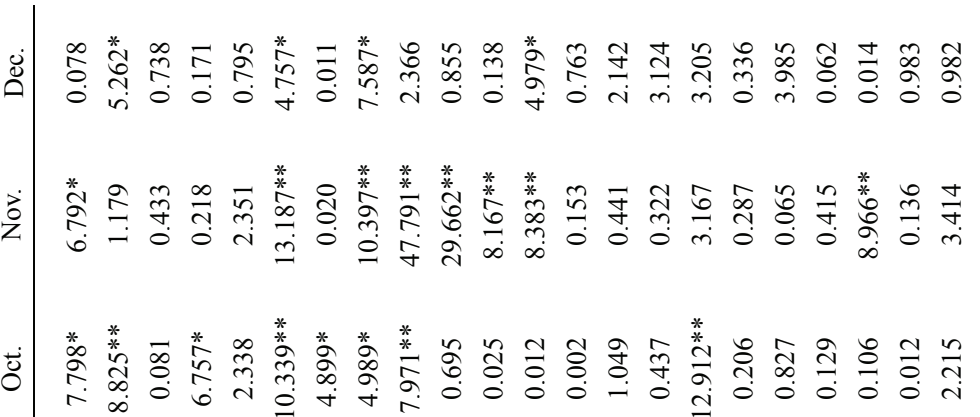

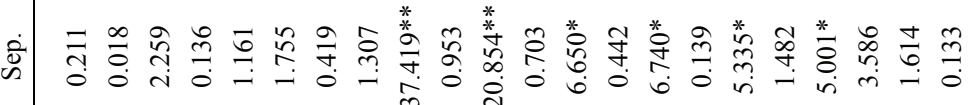

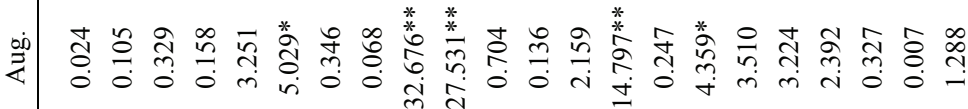

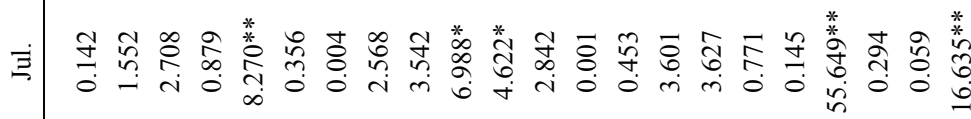

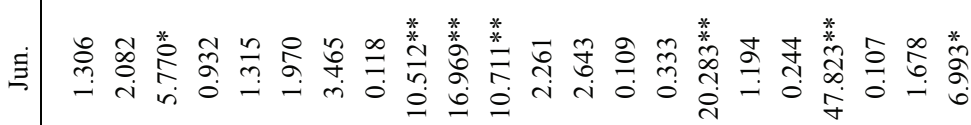

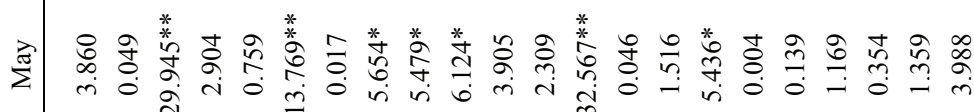

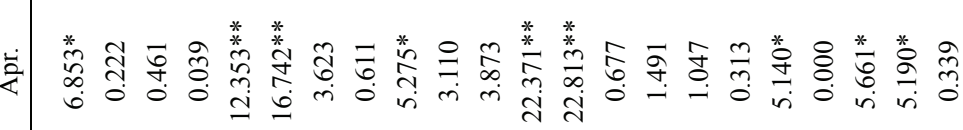

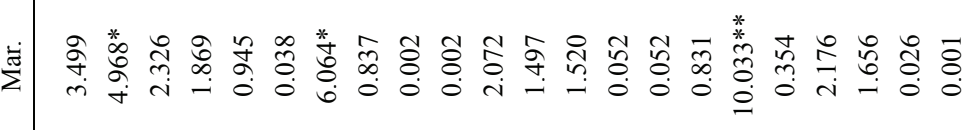

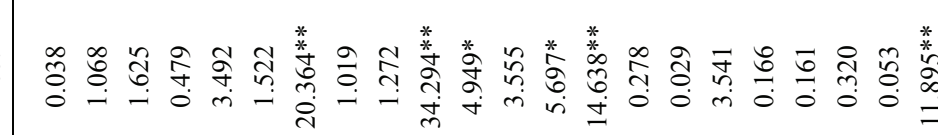

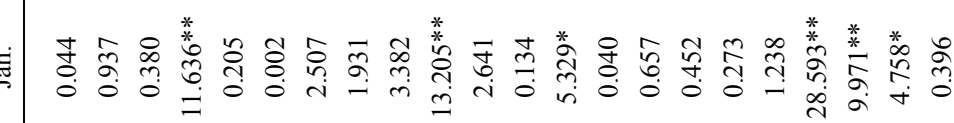

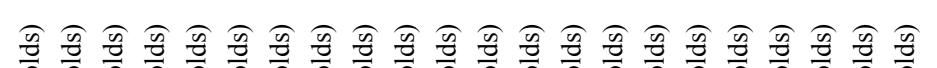

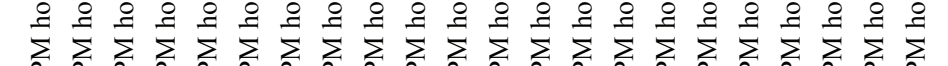

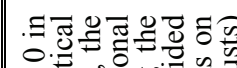

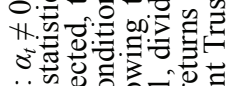

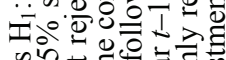

听

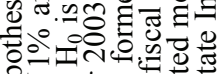

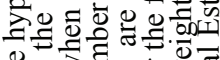

政

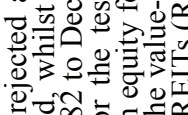

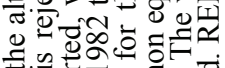

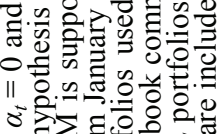

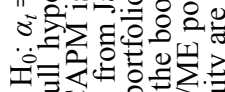

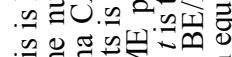

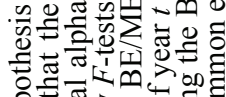

20.

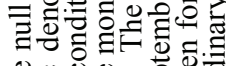

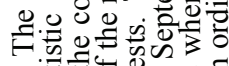

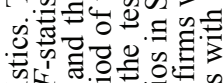

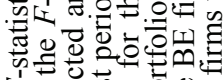

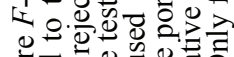

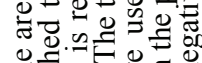

o

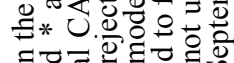

:

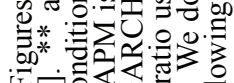

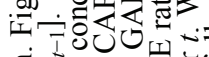

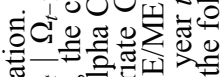

类, 过

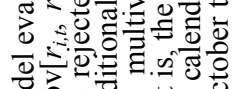

o

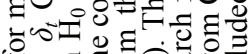

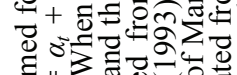

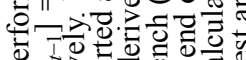

的:

政-

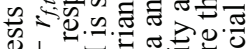

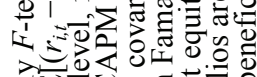

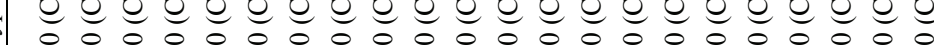

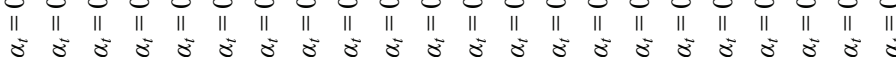

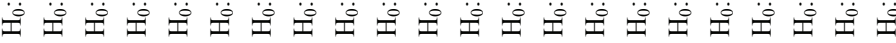

氕

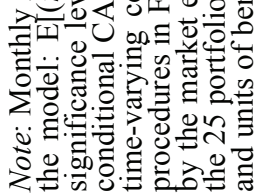


Table 8. Panel data analysis of the time-varying price of risk and the alphas on 25 portfolios formed on the basis of size and BE/ME: the case of the conditional CAPM, the conditional alpha CAPM, and the conditional Consumption CAPM in Japan from October 1981 to July 2004

\begin{tabular}{|c|c|c|c|c|c|c|c|}
\hline \multicolumn{2}{|l|}{$\begin{array}{l}\text { Conditional } \\
\text { CAPM }\end{array}$} & \multicolumn{4}{|l|}{$\begin{array}{l}\text { Conditional } \\
\text { alpha CAPM }\end{array}$} & \multicolumn{2}{|c|}{$\begin{array}{l}\text { Conditional } \\
\text { Consumption CAPM }\end{array}$} \\
\hline Risk price & $p$-value & Intercept & $p$-value & Risk price & $p$-value & Risk price & $p$-value \\
\hline \multicolumn{8}{|c|}{ Panel A Results of 25 portfolios formed on the basis of size } \\
\hline \multicolumn{8}{|c|}{ From October 1981 to July 2004} \\
\hline $0.0382 * *$ & 0.0000 & $1.7165^{* *}$ & 0.0000 & -0.0073 & 0.1995 & 0.0443 & 0.2401 \\
\hline \multicolumn{8}{|c|}{ From October 1981 to December 1986} \\
\hline $0.0952 * *$ & 0.0000 & $3.0591 * *$ & 0.0000 & $-0.0322 *$ & 0.0352 & 0.0820 & 0.3020 \\
\hline \multicolumn{8}{|c|}{ From January 1987 to December 1992} \\
\hline $0.0146^{* *}$ & 0.0015 & $2.0492 * *$ & 0.0000 & $-0.0263 * *$ & 0.0028 & 0.0885 & 0.1379 \\
\hline \multicolumn{8}{|c|}{ From January 1993 to December 1997} \\
\hline $0.0205^{* *}$ & 0.0002 & $-7.0302 * *$ & 0.0000 & $0.2256^{* *}$ & 0.0000 & 0.0377 & 0.5643 \\
\hline \multicolumn{8}{|c|}{ From January 1998 to July 2004} \\
\hline $0.0687^{* *}$ & 0.0000 & $1.4424 * *$ & 0.0033 & 0.0264 & 0.0850 & $-0.4907 * *$ & 0.0075 \\
\hline \multicolumn{8}{|c|}{ Panel B Results of 25 portfolios formed on the basis of BE/ME } \\
\hline \multicolumn{8}{|c|}{ From October 1981 to July 2004} \\
\hline $0.0351 * *$ & 0.0000 & $1.0170^{* *}$ & 0.0000 & 0.0038 & 0.5850 & -0.0222 & 0.5853 \\
\hline \multicolumn{8}{|c|}{ From October 1981 to December 1986} \\
\hline $0.0756^{* *}$ & 0.0000 & $1.2600 * *$ & 0.0076 & 0.0279 & 0.1343 & -0.1185 & 0.2928 \\
\hline \multicolumn{8}{|c|}{ From January 1987 to December 1992} \\
\hline 0.0074 & 0.1278 & 0.5413 & 0.1799 & -0.0060 & 0.5897 & -0.0548 & 0.3911 \\
\hline \multicolumn{8}{|c|}{ From January 1993 to December 1997} \\
\hline $0.0222 * *$ & 0.0000 & $-3.4998 * *$ & 0.0000 & $0.1366 * *$ & 0.0000 & 0.0802 & 0.2050 \\
\hline \multicolumn{8}{|c|}{ From January 1998 to July 2004} \\
\hline $0.0619^{* *}$ & 0.0000 & $0.9485^{*}$ & 0.0367 & 0.0299 & 0.0638 & -0.2335 & 0.2715 \\
\hline \multicolumn{8}{|c|}{$\begin{array}{l}\text { Note: Monthly time-varying price of risk and alphas on } 25 \text { portfolios formed on the basis of size and BE/ME (book } \\
\text { equity to market equity) ratios are evaluated, for the period from October } 1981 \text { to July } 2004 \text { using panel data. The } \\
\text { evaluation is performed for the whole sample period and for four subsample periods. The risk price of the several } \\
\text { versions of conditional asset pricing models is calculated using the conditional time-varying covariances derived from } \\
\text { the multivariate GARCH model. The size- and BE/ME-ranked portfolios are formed following Fama and French } \\
\text { (1993). That is, in constructing the size portfolios, at the end of September of each year } t \text { (1981-2003), TSE (Tokyo } \\
\text { Stock Exchange) First Section stocks are allocated to one of } 25 \text { groups based on their September market equity (ME, } \\
\text { stock price times shares outstanding). Value-weighted monthly returns on the size portfolios are then calculated from } \\
\text { the following October to the next September. When constructing the BE/ME portfolios, the BE/ME ratio used to form } \\
\text { the portfolios in September of year } t \text { is the book common equity for the fiscal year } t-1 \text {, divided by market equity at } \\
\text { the end of March in calendar year } t \text {. We do not use negative BE firms when forming the BE/ME portfolios. The } \\
\text { value-weighted monthly returns on the BE/ME portfolios are then calculated from October to the following } \\
\text { September. Only firms with ordinary common equity are included. This means that REITs (Real Estate Investment } \\
\text { Trusts) and units of beneficial interest are excluded. ** and * attached to the coefficients denote statistical } \\
\text { significance at the } 1 \% \text { and } 5 \% \text { level, respectively. }\end{array}$} \\
\hline
\end{tabular}




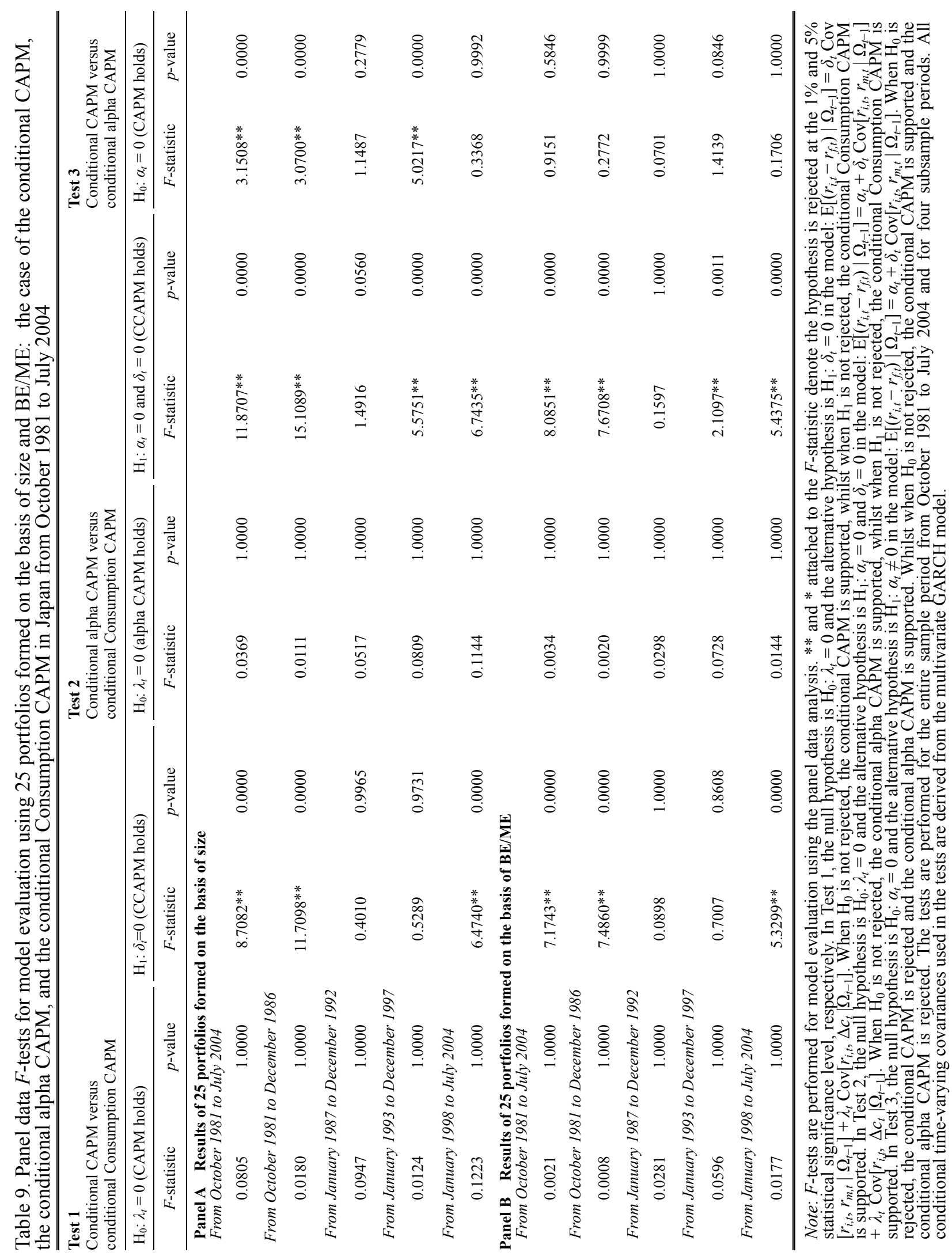


Table 10. Tests of the alphas for the conditional CAPM using 25 portfolios formed on the basis of size and BE/ME: the case in Japan from January 1982 to December 2003

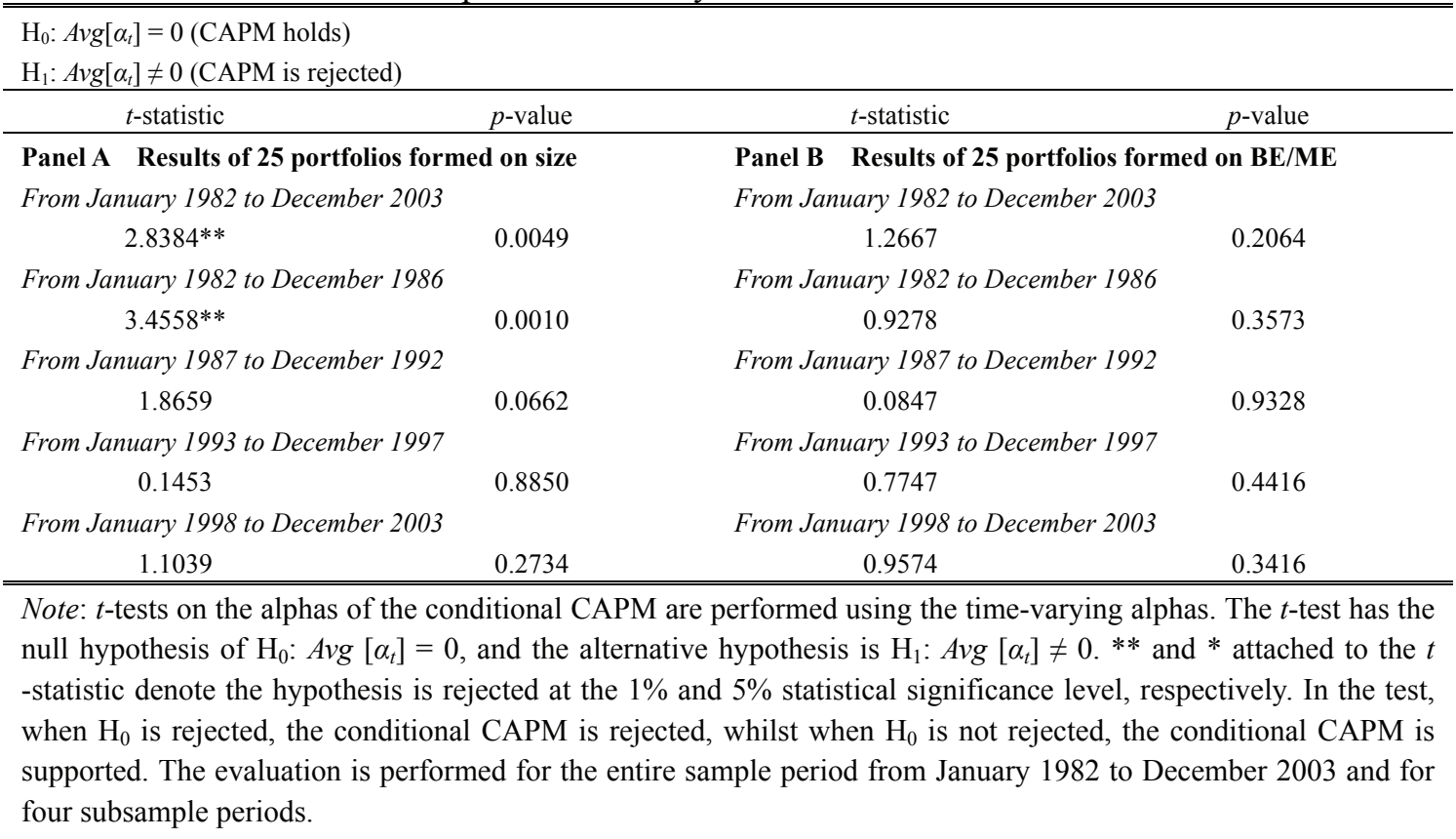

\section{Conclusions}

Considering all the results above, we conclude that our empirical results in Japan offer an interesting case for reconciling the current disputes on the effects of conditioning asset pricing models. Our evidence demonstrates that the conditioning improves model performance in Japan (except for the traditional conditional CCAPM), even if not as dramatically as suggested by Jagannathan and Wang (1996), Lettau and Ludvigson (2001), Santos and Veronesi (2006), and Lustig and Van Nieuwerburgh (2005). The significant facts and implications derived from our analysis are summarized as follows.

- First, from the viewpoint of the risk pricing, we demonstrated that the conditional covariance risk in the CAPM, which is derived from a multivariate GARCH model, is generally positively priced in Japan. We examine the situation in regard to the time-varying risk price, rather than the time-varying covariance risk analysed in many other studies, which is one of our primary contributions in this article.

- Second, our monthly tests for time-varying risk pricing revealed that the conditional CCAPM is not supported in the Japanese stock market. As far as can be judged by the effectiveness of the traditional simple CCAPM, actual Japanese data do not support the model, even if the time-varying nature of both consumption risk and its price are taken into account.

- Third, positive time-varying alphas are confirmed by our tests of the conditional alpha CAPM. In particular, positive alphas are observed in the tests of the size portfolios rather than in the tests of the BE/ME portfolios. 


\section{Macrothink

- Fourth, from the viewpoint of model evaluation, our formal $F$-test indicates that the conditional CCAPM is inferior to the conditional CAPM and the conditional alpha CAPM, not only with respect to the time-varying risk pricing, but also with respect to model evaluation.

- Fifth, in our panel data analysis, the conditional CAPM is not strongly supported and the conditional alpha CAPM is relatively well supported in explaining the size effect in Japan; however, in all cases in explaining the value effect in Japan, the conditional CAPM is always supported and the conditional alpha CAPM is rejected.

- Sixth, we also examined the statistical significance of the non-zero alphas in the conditional CAPM, which is often controversial (e.g. Lewellen and Nagel (2006) and Fama and French (2006)). We confirm that the hypothesis of zero alphas is never rejected for the $\mathrm{BE} / \mathrm{ME}$ portfolios. Thus, when a time-varying risk price is incorporated using the effective multivariate GARCH model, the conditional CAPM explains the value effect in Japan.

Overall, our paper has several noteworthy characteristics, such as 1) a detailed examination of risk pricing, the alphas, and model evaluation; 2) incorporation of both time-varying risks and a time-varying price of risk to analyse the conditional asset pricing model; 3) consideration of both time-series and cross-sectional aspects in evaluating the conditional asset pricing model by panel data analysis; 4) implementation of more direct tests of the effectiveness of the time-varying covariance risk by using a multivariate GARCH model; and 5) detailed discussions and comparisons with the other influential studies.

As the results of this paper suggest, when the time-varying risk price is incorporated into the asset pricing tests by using the multivariate GARCH model, the performance of the conditional CAPM is vastly improved. That is, we conclude that appropriate conditioning of the CAPM by sophisticated methods or models is rather effective for Japan, although such a conditioning does not make the simple CAPM a perfect asset pricing model that competently explains all anomalies in world equity markets.

\section{Acknowledgments}

I especially acknowledge Sabrina Liu (Editor) and Amy Li (Editor) for inviting me to write for this journal. I also thank the anonymous referees for their supportive comments on this paper. I thank the generous financial assistance of the Japan Society for the Promotion of Science and the Zengin Foundation for Studies on Economics and Finance. In addition, I would also like to thank Jason McQueen, Giorgio Szego, Ike Mathur, Geert Bekaert, and Nick Wade for providing very helpful information.

\section{References}

Abel, A. (1990). Asset prices under habit formation and keeping up with the Joneses. American Economic Review Papers and Proceedings, 80, 38-42

Ang, A., \& Chen, J. (2007). CAPM over the long-run: 1926-2001. Journal of Empirical Finance, 14, 1-40 


\section{Macrothink}

Bali, T. G. (2008). The intertemporal relation between expected returns and risk. Journal of Financial Economics, 87, 101-131

Bauwens, L., Laurent, S., \& Rombouts, J. V. K. (2006). Multivariate GARCH models: A survey. Journal of Applied Econometrics, 21, 79-110

Bollerslev, T. (1986). Generalized autoregressive conditional heteroscedasticity. Journal of Econometrics, 31, 207-27

Bollerslev, T., Engle, R. F., \& Wooldridge, J. M. (1988). A capital asset pricing model with time-varying covariances. Journal of Political Economy, 96, 116-31

Braun, P. A., Nelson, D. B., \& Sunier, A. M. (1995). Good news, bad news, volatility, and betas. Journal of Finance, 50, 1575-603

Breeden, D. (1979). An intertemporal asset pricing model with stchastic consumption and investment. Journal of Financial Economics, 7, 265-296

Campbell, J. Y. (1996). Understanding risk and return. Journal of Political Economy, 104, 298-345

Campbell, J. Y., \& Cochrane, J. H. (1999). By forth of habit: A consumption-based explanation of aggregate stock market behavior. Journal of Political Economy, 107, 205-251

Campbell, J. Y., \& Hentchel, L. (1992). No news is good news: an asymmetric model of changing volatility in stock returns. Journal of Financial Economics, 31, 281-318

Chan, K. C., Karolyi, G. A., \& Stulz, R. M. (1992). Global financial markets and the risk premium on US equity. Journal of Financial Economics, 32, 137-167

Chen, N., Roll, R., \& Ross, S. (1986). Economic forces and the stock market. Journal of Business, 59, 383-403

Cochrane, J. H. (1996). A cross-sectional test of an investment-based asset pricing model. Journal of Political Economy, 104, 572-621

Cochrane, J. H. (2005). Asset Pricing. Princeton University Press, New Jersey, USA

Constantinides, G. M. (1990). Habit formation: A resolution of the equity premium puzzle. Journal of Political Economy, 98, 519-543

Engel, C., Frankel, J. A., Froot, K. A., \& Rodrigues, A. P. (1995). Tests of conditional mean variance efficiency on the U.S. stock market. Journal of Empirical Finance, 2, 3-18

Engle, R. F. (1982). Autoregressive conditional heteroscedasticity with estimates of the variance of United Kingdom inflation. Econometrica, 50, 987-1007

Engle, R. F., \& Kroner, K. F. (1995). Multivariate simultaneous generalized ARCH. Econometric Theory, 11, 122-50

Fama, E., \& French, K. (1993). Common risk factors in the returns on stocks and bonds. Journal of Financial Economics, 33, 3-56 
Fama, E., \& French, K. (1996). Multifactor explanations of asset pricing anomalies. Journal of Finance, 51, 55-84

Fama, E., \& French, K. (2006). The Value Premium and the CAPM. Journal of Finance, 61, 2163-2185

Ferson, W. E., \& Harvey, C. R. (1994). Sources of risk and expected returns in global equity markets. Journal of Banking \& Finance, 18, 775-803

Ferson, W. E., \& Schadt, R. (1996). Measuring fund strategy and performance in changing economic conditions. Journal of Finance, 51, 425-462

French, K. R., Schwert, G. W., \& Stambaugh, R. F. (1987). Expected stock returns and volatility. Journal of Financial Economics, 19, 3-29

Gibbons, M. R., Ross, S. A., \& Shanken, J. (1989). A test of the efficiency of a given portfolio. Econometrica, 57, 1121-1152

Glosten, L. R., Jagannathan, R., \& Runkle, D. E. (1993). On the relation between the expected value and the volatility of the nominal excess returns on stocks. Journal of Finance, $48,1779-1801$

Guo, H. (2006). Time-varying risk premia and the cross section of stock returns. Journal of Banking \& Finance, 30, 2087-2107

Hamao, Y. (1988). An empirical examination of the arbitrage pricing theory. Japan and the World Economy, 1, 45-61

Hansson, B., \& Hördahl, P. (1998). Testing the conditional CAPM using multivariate GARCH-M. Applied Financial Economics, 8, 377-388

Harvey, C. R. (1989). Time-varying conditional covariances in tests of asset pricing models. Journal of Financial Economics, 24, 289-317

Jagannathan, R., \& Wang, Z. (1996). The Conditional CAPM and the Cross-Section of Expected Returns. Journal of Finance, 51, 3-53

Jensen, M. C. (1968). The Performance of Mutual Funds in the Period 1945-1964. Journal of Finance, 23, 389-416

Kroner, K. F., \& Ng, V. K. (1998). Modeling Asymmetric Comovement of Assets Returns. Review of Financial Studies, 11, 817-844

Lettau, M., \& Ludvigson, S. (2001). Resurrecting the (C)CAPM: A Cross-Sectional Test When Risk Premia Are Time-Varying. Journal of Political Economy, 109, 1238-1287

Lewellen, J., \& Nagel, S. (2006). The conditional CAPM does not explain asset-pricing anomalies. Journal of Financial Economics, 82, 289-314

Li, G. (2007). Time-varying risk aversion and asset price. Journal of Banking \& Finance, 31, $243-257$ 


\section{Macrothink Institute $^{\mathrm{TM}}$}

Lintner, J. (1965). The valuation of risky assets and the selection of risky investments in stock portfolios and capital budgets. Review of Economics and Statistics, 47, 13-37

Lundblad, C. (2007). The risk return tradeoff in the long run: 1836-2003. Journal of Financial Economics, 47, 13-37

Lustig, H., \& Van Nieuwerburgh, S. (2005). Housing collateral, consumption insurance, and risk premia: an empirical perspective. Journal of Finance, 85, 123-150

Maddala, G. S. (1992). Introduction to econometrics. Prentice-Hall, Inc., New Jersey, USA

Mankiw, N. G., \& Zeldes, S. P. (1991). The Consumption of Stockholders and Nonstockholders. Journal of Financial Economics, 29, 97-112

Mehra, R., \& Prescott, E. C. (1985). The Equity Premium: A Puzzle. Journal of Monetary Economics, 15, 145-161

Merton, R. C. (1973). An intertemporal capital asset pricing model. Econometrica, 41, $867-887$

Merton, R. C. (1980). On estimating the expected return on the market. Journal of Financial Economics, 8, 323-61

Mossin, J. (1966). Equilibrium in a Capital Asset Market. Econometrica, 34, 768-783

Nelson, D. B. (1991). Conditional heteroskedasticity in asset returns: A new approach. Econometrica, 59, 347-70

$\mathrm{Ng}$, L. (1991). Tests of the CAPM with time-varying covariances: A multivariate GARCH approach. Journal of Finance, 46, 1507-21

Petkova, R., \& Zhang, L. (2005). Is value riskier than growth? Journal of Financial Economics, 78, 187-202

Polk, C., Thompson, S., \& Vuolteenaho, T. (2006). Cross-sectional forecasts of the equity premium. Journal of Financial Economics, 81, 101-141

Rubinstein, M. (1976). The valuation of uncertain income streams and the pricing of options. Bell Journal of Economics, 7, 407-425

Santos, T., \& Veronesi, P. (2006). Labor income and predictable stock returns. Review of Financial Studies, 19, 1-44

Scruggs, J. T. (1998). Resolving the puzzling intertemporal relation between the market risk premium and conditional market variance: a two-factor approach. Journal of Finance, 53, 575-603

Shanken, J. (1990). Intertemporal asset pricing: an empirical investigation. Journal of Econometrics, 45, 99-120

Sharpe, W. (1964). Capital asset prices: A theory of market equilibrium under conditions of risk. Journal of Finance, 19, 425-42 
White, H. (1980). A Heteroskedasticity-Consistent Covariance Matrix Estimator and Direct Test for Heteroskedasticity. Econometrica, 48, 817-838

Zhou, G. (1994). Analytical GMM tests: asset pricing with time-varying risk premiums. Review of Financial Studies, 7, 687-709

\section{Notes}

1. For example, interesting papers that deal with the price of risk include Harvey (1989), Ferson and Harvey (1994), Campbell (1996), and Hansson and Hördahl (1998). However, in these studies, the price of risk is not their main concern.

2. Polk et al. (2006) also perform an interesting empirical analysis by exploiting the price of risk; however, both their aim and their approach are different from those of our study.

3. Bollerslev et al. (1988) perform one of the first multivariate analyses in a test of CAPM. Other studies that use the multivariate GARCH model in the context of asset pricing include Chan et al. (1992), Braun et al. (1995), Kroner and Ng (1998), Scruggs (1998), and Bali (2008); however, the focus of the above interesting studies is not on the price of risk. On the other hand, many studies on the variation of financial asset prices using univariate GARCH models exist; those include Engle (1982), Bollerslev (1986), French et al. (1987), Nelson (1991), Campbell and Hentchel (1992), Glosten et al. (1993), and Lundblad (2007).

4. The time-varying price of risk in the CAPM is, in particular, economically important, because it is interpreted as time-varying risk aversion. We discuss this point in Section 3.

5. Because we investigate the size effect and value effect separately, we employed size and $\mathrm{BE} / \mathrm{ME}-$ ranked portfolios in this paper.

6. In our tests, we use the multivariate GARCH model for two reasons. First, the model enables us to perform a direct test to judge whether the time-varying covariance risk is priced. That is, we can inspect the relationship between risk and risk price by using the time-varying covariance via the multivariate GARCH model. Second, this multivariate GARCH-asset pricing approach does not place any assumptions on the state variables, unlike the approaches of Shanken (1990), Ferson and Schadt (1996), and Lettau and Ludvigson (2001), for example. This is also one of the advantages of our approach because placing any assumptions on the state variables is a restricted way of conditioning asset pricing models. Despite these advantages of the multivariate GARCH model, as we mentioned previously, research into asset pricing using the multivariate GARCH models is limited.

7. The term alpha is used in this paper in the sense of Jensen (1968).

8. Lewellen and Nagel (2006) criticize Jagannathan and Wang (1996), Lettau and Ludvigson (2001), Santos and Veronesi (2006), and Lustig and Van Nieuwerburgh (2005) for not providing a full, quantitative test of the conditional CAPM. Fama and French (2006) insist that in a CAPM world, the true intercept is zero. We provide a detailed discussion on these points in Section 8.

9. Ang and Chen (2007) find that the CAPM can explain US value premiums from 1926 to 
1963, whilst Fama and French (2006) reject CAPM pricing for 1928-1963, as well as for 1963-2004.

10. From a cross-sectional perspective, the model implies that the conditional expected excess returns vary with the different conditional beta values or different conditional covariances. From a time-series perspective, the model has the implication that the conditional expected excess returns change over time with three time-varying components: the conditional market risk premium, the market conditional variance, and the conditional covariance between an asset's return and the market's return.

11. Before June 1984, one-month CD rates are not available. Thus, following Hamao (1988), we specified the gensaki rate as the risk-free rate before June 1984.

12. Because each regression comprises a cross-section, White's (1980) heteroskedasticity-consistent covariance matrix was used to calculate the $p$-values. We employed White's (1980) covariance matrix throughout the paper when cross-sectional regressions were implemented.

13. From Figures 1 to 8, the time span is always from January 1982 to December 2003.

14. To save space, we did not attach tables of the values of risk prices with their $p$-values. However, they are available from the authors upon request.

15. Because this paper does not employ the GMM approach as in Harvey (1989), Cochrane (1996), and Guo (2006), amongst others, but employs the multivariate GARCH approach, we do not implement the $J$-test, the most typical test for the GMM approach, but perform the $F$-test.

16. Under $H_{0}: \lambda_{t}=0$, the restricted model is the conditional CAPM (4), and under $H_{1}: \delta_{t}=0$, the restricted model is the conditional CCAPM (6).

17. It is possible that both models are rejected or both models are supported.

18. Under $H_{0}: \lambda_{t}=0$, the restricted model is the conditional alpha CAPM (5), and under $H_{1}: \alpha_{t}$ $=0$ and $\delta_{t}=0$, the restricted model is the conditional CCAPM (6).

19. Again, it is possible that both models are rejected or both models are supported.

20. This paper does not test the consumption-wealth ratio, cay, of Lettau and Ludvigson (2001). Because cay is a quarterly variable, incorporation of cay is inconsistent with our research design of monthly tests and panel data model evaluation by pooling monthly data. Therefore, our empirical denegation on the conditional CCAPM in Japan is limited to the traditional standard version. The validity of the conditional CCAPM that incorporates cay in Japan is an open question.

21. Similarly to the previous test, RRSS is the sum of squared residuals of the restricted model (4) or (6). URSS is the sum of squared residuals of the unrestricted model (13), $r$ is the number of restrictions, $n$ is the number of samples in each month, $T$ is the number of months in the sample period tested, and $k$ is the number of explanatory variables in the unrestricted 
model (13).

22. Similarly to the previous test, RRSS is the sum of squared residuals of the restricted model (5) or (6), URSS is the sum of squared residuals of the unrestricted model (15), $r$ is the number of restrictions, $n$ is the number of samples in each month, $T$ is the number of months in the period tested, and $k$ is the number of explanatory variables in the unrestricted model (15).

23. Similarly to the previous test, RRSS is the sum of squared residuals of the restricted model (4), URSS is the sum of squared residuals of the unrestricted model (5), $r$ is the number of restrictions, $n$ is the number of samples in each month, $T$ is the number of months in the period tested, and $k$ is the number of explanatory variables in the unrestricted model (5).

24. However, because our evidence indicates that the conditional CAPM cannot successfully explain the return dispersion of the size portfolios, we cannot fully support the conditional CAPM in Japan.

25. Our alphas are the time-varying alphas $\alpha_{t}$, and not the time-invariant alpha $\alpha$, which is like that obtained from a single time-series regression as in Fama and French (1996). Therefore, we do not implement the famous $F$-test of Gibbons et al. (1989) because it is not suitable for our context of analysis in this paper. 